Acta Crystallographica Section B

Structural

Science

ISSN 0108-7681

\section{David Santamaría-Pérez and Angel Vegas*}

Instituto de Química-Física 'Rocasolano', CSIC, C/Serrano 119, E-28006 Madrid, Spain

Correspondence e-mail: avegas@iqfr.csic.es

\title{
The Zintl-Klemm concept applied to cations in oxides. I. The structures of ternary aluminates
}

The structures of 94 ternary aluminates are reinterpreted on the basis of the Zintl-Klemm concept and Pearson's generalized octet rule. In aluminates of highly electropositive metals such as alkali, alkaline-earth and rare-earth metals, the $\mathrm{Al}$ atoms form three-dimensional skeleta which can be interpreted as if the $\mathrm{Al}$ atoms were behaving as Zintl polyanions, adopting the structure of either main-group elements or Zintl polyanions showing the same connectivity. The $\mathrm{O}$ atoms are then located close to both the hypothetical two-electron bonds and the lone pairs, giving rise to a tetrahedral coordination. When more electronegative elements, such as $\mathrm{W}$ or $\mathrm{Si}$, are present in the compound, the electron transfer towards the $\mathrm{Al}$ atoms does not take place. In this case, aluminium behaves as a base, transferring its electrons to the more electronegative atoms and the coordination sphere of aluminium becomes octahedral. In some compounds the $\mathrm{Al}$ atoms clearly show amphoteric character so that some $\mathrm{Al}$ atoms act as donors (bases) and hence are octahedrally coordinated, whereas others behave as acceptors (acids), adopting a tetrahedral coordination. From this it is concluded that the coordination sphere of aluminium is not a function of the ionic radius of the $\mathrm{Al}^{3+}$ cations, but it depends on the nature of the other cations accompanying them in the structure. The networks formed by these aluminates are, in many instances, similar to those of the binary oxides of the main-group elements. For this reason, a systematic survey of these oxides is also reported. Compounds such as stuffed cristobalites and trydimites and also perovskites are examples of this new interpretation. Perovskites are then reinterpreted as a stuffed pseudo- $\mathrm{TeO}_{3}$ structure. Other families of compounds such as silicates and phosphates are susceptible to a similar interpretation. This study provides additional examples of how cations recognize themselves in spite of being embedded in an oxygen matrix.

\section{Introduction}

Aluminates, ternary and quaternary oxides of aluminium, have been widely studied. The Inorganic Crystal Structure Database (ICSD) contains 94 phases of ternary aluminates.

A structural characteristic of these aluminates is the variability in the coordination sphere of the $\mathrm{Al}$ atoms. In most cases, aluminium appears either tetrahedrally or octahedrally coordinated and only in a few compounds does aluminium appear as five-coordinated by $\mathrm{O}$ atoms. Moreover, in some compounds two types of coordination polyhedra coexist. This is the case for the mineral andalusite $\left(\mathrm{Al}_{2} \mathrm{SiO}_{5}\right)$, where fiveand six-coordinated $\mathrm{Al}$ atoms are found, or compounds such
Received 19 December 2002

Accepted 10 March 2003
(C) 2003 International Union of Crystallography Printed in Great Britain - all rights reserved 
as sillimanite $\left(\mathrm{Al}_{2} \mathrm{SiO}_{5}\right), \mathrm{Al}_{5} \mathrm{BO}_{3}, \mathrm{FeAlO}_{3}$ and $\mathrm{Sr}_{4} \mathrm{Al}_{14} \mathrm{O}_{25}$, where both $\mathrm{Al}(\mathrm{O})_{4}$ tetrahedra and $\operatorname{Al}(\mathrm{O})_{6}$ octahedra are present.

This variability in the coordination number of aluminium has not been explained satisfactorily since it is based on geometrical factors (the radius ratio $r_{+} / r_{-}$) and consequently it depends on the ionic radii set we use to calculate the ratio. Thus, if we take the radii of Shannon \& Prewitt (1969), the $r_{+} / r_{-}$ratio has the values 0.2867 and 0.3897 for $\mathrm{Al}^{\mathrm{IV}}$ and $\mathrm{Al}^{\mathrm{VI}}$, respectively. With these values, the $\mathrm{Al}$ atoms would necessarily occupy tetrahedral holes (limiting ratio for the tetrahedral coordination, 0.414). If the set of Pauling (1960) is considered, the $r_{+} / r_{-}$ratio (0.357) also predicts a tetrahedral coordination. Only if the univalent radii are used does the $r_{+} / r_{-}$ratio have a value of 0.41 , which is close to the upper limit for tetrahedral coordination and which is the lower limit for octahedral coordination. Thus, these univalent radii (when applicable) should be the only geometrical support to the variable coordination of aluminium in their oxides. However, it should be pointed out that an $r_{+} / r_{-}$ratio of 0.40 (compared with 0.41 ) is considered to be an overwhelming argument to justify the tetrahedral coordination of $\mathrm{Zn}^{2+}$ cations in $\mathrm{ZnS}$.

Another structural feature of aluminates is the constancy of the $\mathrm{Al}-\mathrm{Al}$ distances. In recent work Isea et al. (1998) have shown that the distribution of the $\mathrm{Al}-\mathrm{Al}$ distances in all aluminium oxides is not homogeneous, but it presents two maxima. The first is a sharp maximum which is centered at $2.86 \AA$, just the value of the $\mathrm{Al}-\mathrm{Al}$ distance in f.c.c. $\mathrm{Al}$ (facecentered cubic). This distance corresponds to the separation between two $\mathrm{Al}$ atoms which occupy edge-sharing octahedra. The structures of spinels $\left(A^{\mathrm{IV}} M^{\mathrm{VI}}{ }_{2} \mathrm{O}_{4}\right)$ and delafossites $\left(A^{\mathrm{II}} M^{\mathrm{VI}} \mathrm{O}_{2}\right)$ were therefore interpreted as formed by fragments of a f.c.c.-Al net (Isea et al., 1998). The same feature was observed in aluminium oxides, hydroxides and oxyhydroxides (Ramos-Gallardo \& Vegas, 1995, 1996). The second maximum is broader and is centered at around $3.3 \AA$. It is coincident with the distribution of distances $(\mathrm{Al}-\mathrm{Al})$ between two $\mathrm{Al}$ atoms (normally tetra-coordinated) bridged by one single $\mathrm{O}$ atom, from which O'Keeffe \& Hyde (1981) assigned a value of $1.62 \AA$ to the non-bonded or 'one-angle' radius of $\mathrm{Al}^{3+}$. An example of this behaviour is $\mathrm{NaAlO}_{2}$ (Kaduk \& Pei, 1995) in which the $\mathrm{AlO}_{4}$ tetrahedra share corners to form a threedimensional array where the $\mathrm{Al}-\mathrm{Al}$ contacts are $3.21 \AA$.

From these studies (Ramos-Gallardo \& Vegas, 1996; Isea et al., 1998), it was concluded that the structures with hexacoordinated $\mathrm{Al}$ atoms reproduce topology and distances of the elemental metal structure, and hence they could be related to it. However, in compounds with tetra-coordinated aluminium, the $\mathrm{Al}(\mathrm{O})_{4}$ tetrahedra form networks which, in most cases, have been poorly described as complicated and capricious arrangements whose connectivity has not been understood and hence could not be related to any known elemental structure. Only in some compounds are these three-dimensional tetrahedral networks related to other $X(\mathrm{O})_{4}$ tetrahedral skeleta. This is the case for $\mathrm{KAlO}_{2}$ (stuffed cristobalite structure), in which the KAl subarray is that of the Zintl phase LiAl (O'Keeffe \& Hyde, 1985), and the above-mentioned
$\mathrm{NaAlO}_{2}$, which also adopts a distorted cristobalite structure. Other examples of stuffed quartz, trydimite, cristobalite and keatite structures are collected in chapter 23 of the treatise Structural Inorganic Chemistry (Wells, 1975).

These features, together with the structural similarity found between the Zintl phase $\mathrm{CaAl}_{2} \mathrm{Si}_{2}$ and the corresponding aluminosilicate $\mathrm{CaAl}_{2} \mathrm{Si}_{2} \mathrm{O}_{8}$ (Vegas \& Santamaría-Pérez, 2003), led us to think that the Zintl-Klemm concept could be maintained in the oxides and that its application to aluminates could help us to rationalize and explain the rather complicated networks found in this family of compounds which, on the other hand, cannot be explained in terms of the Pauling's $r_{+} / r_{-}$ ratio.

The application of the Zintl-Klemm concept could be reasonable for the following reasons: on one hand because there are some main group elements whose structure is topologically maintained in their oxides. This occurs for example in two varieties of $\mathrm{SiO}_{2}$ such as cristobalite and trydimite, where the $\mathrm{Si}$ atoms preserve the structures of elemental silicon (diamond-like and londsdaleite-like, respectively) and also in keatite whose silicon array is that of an HP phase of Ge (Wells, 1975). Other examples are provided by the $\mathrm{P}_{4}$ molecules and the corresponding oxides $\mathrm{P}_{4} \mathrm{O}_{6}, \mathrm{P}_{4} \mathrm{O}_{8}$, $\mathrm{P}_{4} \mathrm{O}_{9}$ and $\mathrm{P}_{4} \mathrm{O}_{10}$, where the $\mathrm{P}_{4}$ skeleton is preserved. This coincidence was already pointed out by Addison (1965). On the other hand, because aluminium is an element at the Zintl border (Miller, 1996) which is in the presence of very electropositive cations, it can behave as a Zintl polyanion (remember the case of LiAl mentioned above) and the polyanion networks could be maintained in the oxides.

As is well known, the Zintl concept (Zintl, 1939), later extended by Klemm (1958), is that in compounds $A_{x} X_{y}$, where $A$ is a very electropositive element relative to a main-group element $X$, the structure can be thought of as if the $A$ atoms transfer their valence electrons to the $X$ atoms which use them to form $X-X$ bonds. The number of bonds formed obey the $8-N$ rule. When heterogeneous $X$ species are formed, then the $X$ skeleton can be explained by the generalized octet rule (Pearson, 1964).

The first attempt to correlate the connection between tetrahedra with composition is due to Parthé \& Engel (1986). Furthermore, the Zintl-Klemm concept was applied by Parthé \& Chabot (1990) to deduce the connectivity in structures with anionic tetrahedron complexes of the general formula $C_{m} C_{m^{\prime}}^{\prime} A_{n}$. From valence-electron criteria they deduced expressions which allow the prediction of tetrahedral sharing numbers, as well as the formation of $C^{\prime}-C^{\prime}$ and $A-A$ bonds.

We report here a systematic study of the structures of all the ternary aluminates contained in the ICSD. The Al subarrays will be analysed in the light of both the Zintl concept and the generalized octet rule (Pearson, 1964). We will see that these two old concepts will help us to understand both the coordination sphere of the $\mathrm{Al}$ atoms and the three-dimensional array of these complicated frameworks. One of these old concepts, the Zintl concept, is the single most important theoretical concept in solid state chemistry of this century, in the opinion of Hoffmann (1988). 
The study begins with a survey of the structures of all the oxides of the main group elements with which the aluminate networks could be related.

\section{Discussion}

\subsection{Binary oxides of main-group elements}

The known oxides of the main group elements (hereafter referred to as $X$ ) are collected in Table 1 . Table 1 also contains both the elements and the Zintl polyanions with which the cationic $X$ substructures are related.

For the group 14 elements, the similarity between the elemental structures and those of the oxides is straightforward. We have mentioned in $\S 1$ that the $X$-subarray in trydimite and cristobalite are topologically identical to hexagonal (wurtzite-like) and cubic (diamond-like) silicon, respectively. The cristobalite structure also exists for $\mathrm{GeO}_{2} \cdot \mathrm{CO}_{2}$, which under normal conditions is a molecule, adopts the structure of quartz at very high pressures (above $40 \mathrm{GPa}$ and $1800 \mathrm{~K}$; Iota et al., 1999). The same structure exists for $\mathrm{SiO}_{2}$ and $\mathrm{GeO}_{2}$. In quartz the $X$ atoms adopt a structure formed by triangular and hexagonal helices which do not correspond to any structure of the Group 14 elements, but it is identical to that of the Si-rich compound $\mathrm{CrSi}_{2}$ (Mattheiss, 1992) represented in Fig. 1. In addition, the subarray of $X$ atoms in keatite corresponds to an HP (high-pressure) phase of Ge (Wells, 1975). More recently, O'Keeffe \& Hyde (1985) reported the similarities between the $\mathrm{Si}$ array in both $\mathrm{K}_{4} \mathrm{Si}_{23}$ and the silica-rich mineral melanophlogite. Other varieties of silica exist, such as ferrierite, moganite and chabazite, whose $\mathrm{Si}$ substructures do not correspond to any structure of the elements but where the four-connectivity is maintained.

Finally, the rutile-type structure is observed for $\mathrm{HP}-\mathrm{SiO}_{2}$ (stishovite), $\mathrm{GeO}_{2}, \mathrm{SnO}_{2}$ and $\beta$ - $\mathrm{PbO}_{2}$. In these structures, as in rutile, the cation array (body-centered tetragonal, b.c.t.) corresponds to an expansion of the b.c.t. structure of the HP $\gamma$ Sn (Barnett et al., 1986). Thus, in all the Group 14 oxides the cation arrays correspond either to the structures of elements of the group or to structures of Si-rich compounds.

In Group 15 similar behaviour is observed. For phosphorus, five oxides are known, i.e. $\mathrm{P}_{4} \mathrm{O}_{6}$ (Jansen et al., 1981), $\mathrm{P}_{4} \mathrm{O}_{7}$ (Jost \& Schneider, 1981; Moebs \& Jansen, 1984), $\mathrm{P}_{4} \mathrm{O}_{8}$ (Beagley et
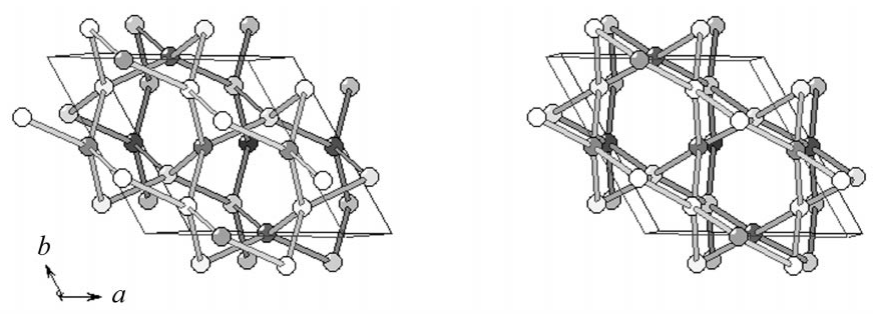

\section{Figure 1}

Stereopair of the structure of $\mathrm{CrSi}_{2}$. Dark grey circles are $\mathrm{Cr}$ atoms. Medium grey circles are $\mathrm{Si}$ atoms. Both atoms form trigonal and hexagonal helices as the $\mathrm{Si}$ atoms in quartz. All figures were prepared using DIAMOND (Crystal Impact, 1998). al., 1969; Jansen \& Strojek, 1997), $\mathrm{P}_{4} \mathrm{O}_{9}$ (Jost, 1964; Beagley et al., 1967; Lueer \& Jansen, 1991) and $\mathrm{P}_{4} \mathrm{O}_{10}$ (Cruickshank, 1964; Arbib et al., 1996). One unique phase is known for all of them except $\mathrm{P}_{4} \mathrm{O}_{10}$, of which three phases have been reported. All these oxides, except $\mathrm{P}_{4} \mathrm{O}_{7}$, maintain the skeleton of the $\mathrm{P}_{4}$ molecule. In Fig. 2 the structures of $\mathrm{P}_{4}, \mathrm{P}_{4} \mathrm{O}_{6}$ and $\mathrm{P}_{4} \mathrm{O}_{10}$ are represented. As seen, when six $\mathrm{O}$ atoms are located close to the $\mathrm{P}-\mathrm{P}$ bonds, the $\mathrm{P}_{4} \mathrm{O}_{6}$ molecule is formed. When more $\mathrm{O}$ atoms are added, close to the positions of the $\mathrm{P}$ lone pairs, the $\mathrm{P}_{4} \mathrm{O}_{8}, \mathrm{P}_{4} \mathrm{O}_{9}$ and $\mathrm{P}_{4} \mathrm{O}_{10}$ oxides are formed. The exception to this rule is $\mathrm{P}_{4} \mathrm{O}_{7}$, in which the $\mathrm{P}_{4}$ tetrahedron is broken in such a way that the apical $\mathrm{P}$ atom is displaced, breaking two $\mathrm{P}-\mathrm{P}$ bonds. In the second phase of $\mathrm{P}_{2} \mathrm{O}_{5}$, phosphorus adopts the layer structure of elemental As and also that of the $\mathrm{Si}$ atoms (pseudo-phosphorus) in $\mathrm{CaSi}_{2}$. In the third phase the $\mathrm{P}$ atoms arrange as the $\mathrm{Si}$ atoms (pseudo-phosphorus atoms) in the HP Zintl phase $\mathrm{SrSi}_{2}$ (Evers et al., 1983) or in $\mathrm{BaGe}_{2}$ (Evers et al., 1980). This structure is represented in Fig. 3 and consists of a three-connected net forming 12- and ten-membered rings.

Five phases have been reported for the arsenic oxides, i.e. two for $\mathrm{As}_{2} \mathrm{O}_{3}$, one for $\mathrm{AsO}_{2}$ and two for $\mathrm{As}_{2} \mathrm{O}_{5}$. In the first phase of $\mathrm{As}_{2} \mathrm{O}_{3}$, the As atoms reproduce the topology of the layered three-connected net of the elemental As (Fig. 4;
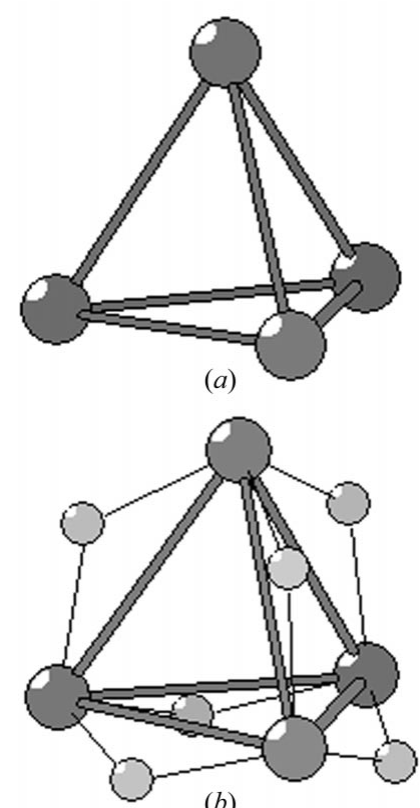

(b)

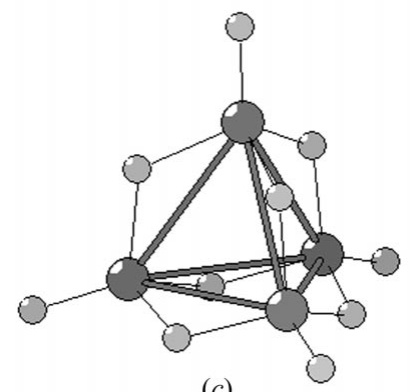

(c)

Figure 2

The molecules of $(a) \mathrm{P}_{4},(b) \mathrm{P}_{4} \mathrm{O}_{6}$ and (c) $\mathrm{P}_{4} \mathrm{O}_{10}$. 
Table 1

The binary oxides of the main-group elements whose cation arrays are coincident with either the structure of the respective elements or simple binary compounds.

\begin{tabular}{|c|c|}
\hline Oxides preserving the elemental structures & Elemental or alloy structures \\
\hline $\begin{array}{l}\mathrm{SiO}_{2} \text { (cristobalite), } \mathrm{GeO}_{2} \mathrm{BPO}_{4}, \mathrm{BeSO}_{4}, \\
\quad \mathrm{ZnSO}_{4}(\mathrm{HT})\end{array}$ & $\begin{array}{l}\mathrm{Si} \text { (diamond) } \mathrm{BP}, \mathrm{BeS}, \mathrm{ZnS} \\
\text { (blende) }\end{array}$ \\
\hline $\mathrm{SiO}_{2}$ (trydimite) $\mathrm{BPO}_{4}$ & $\mathrm{C}, \mathrm{Si}$ (hexagonal) \\
\hline $\mathrm{SiO}_{2}$ (quartz), $\mathrm{GeO}_{2}, \mathrm{CO}_{2} \mathrm{BPO}_{4}, \mathrm{AlPO}_{4}$ & $\mathrm{CrSi}_{2}$ \\
\hline $\mathrm{SiO}_{2}$ (keatite) & $\mathrm{Ge}(\mathrm{HP})$ \\
\hline $\mathrm{SiO}_{2}$ (stishovite), $\mathrm{GeO}_{2}, \mathrm{SnO}_{2}, \beta-\mathrm{PbO}_{2}$ & Sn (HP) \\
\hline Melanophlogite & $\mathrm{K}_{4} \mathrm{Si}_{23}$ \\
\hline $\mathrm{AlPO}_{4}$ (metavariscite) & $\mathrm{CrB}_{4}, \beta-\mathrm{BeO}$ \\
\hline $\mathrm{AlPO}_{4}$ (variscite) & Si (HP)-related \\
\hline $\mathrm{SnO}(\mathrm{HP})$ & \\
\hline $\begin{array}{l}\mathrm{P}_{4} \mathrm{O}_{6}, \mathrm{P}_{4} \mathrm{O}_{8}, \mathrm{P}_{4} \mathrm{O}_{9}, \mathrm{P}_{4} \mathrm{O}_{10}, \mathrm{As}_{2} \mathrm{O}_{3}, \mathrm{Sb}_{4} \mathrm{O}_{6} \\
\quad \mathrm{Sb}_{4} \mathrm{O}_{10}\end{array}$ & $\mathrm{P}_{4}$ (molecules) \\
\hline 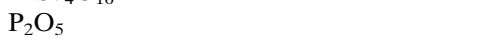 & $\mathrm{SrSi}_{2}(\mathrm{HP}), \mathrm{BaGe}_{2}, \mathrm{ThSi}_{2}$ \\
\hline $\begin{array}{l}\mathrm{P}_{2} \mathrm{O}_{5}, \mathrm{As}_{2} \mathrm{O}_{3} \\
\mathrm{P}_{4} \mathrm{O}_{7}\end{array}$ & As (layers), $\mathrm{CaSi}_{2}$ \\
\hline $\mathrm{As}_{2} \mathrm{O}_{5}$ (two phases) & $\mathrm{SrSi}_{2}$ (ambient pressure) \\
\hline $\mathrm{As}_{2} \mathrm{O}_{4}$ & \\
\hline $\mathrm{Sb}_{2} \mathrm{O}_{3}$ & \\
\hline $\mathrm{Sb}_{2} \mathrm{O}_{5}, \mathrm{Sb}_{2} \mathrm{O}_{4}, \mathrm{Bi}_{2} \mathrm{O}_{4}$ & $\mathrm{Bi}, \mathrm{Sb}(\mathrm{HP})$ \\
\hline $\mathrm{Bi}_{2} \mathrm{O}_{3}$ & \\
\hline $\mathrm{SO}_{3}, \mathrm{SeO}_{2}, \mathrm{Se}_{2} \mathrm{O}_{5}, \gamma-\mathrm{TeO}_{2}$ & S (chains) asbestos-like \\
\hline $\mathrm{S}_{3} \mathrm{O}_{9}$ & $\mathrm{~S}_{3}($ molecule $)$ \\
\hline $\mathrm{Se}_{4} \mathrm{O}_{12}$ & $\mathrm{~S}_{4}$ (molecule) \\
\hline $\mathrm{TeO}_{3}$ & Te (HP), Po \\
\hline $\mathrm{TeO}_{2}$ & $\mathrm{~S}_{2}$ (molecule) \\
\hline
\end{tabular}

Frueh, 1951). In the second phase (Lihl, 1932), $\mathrm{As}_{2} \mathrm{O}_{3}$ adopts the structure of $\mathrm{P}_{4} \mathrm{O}_{6}$ where the $\mathrm{As}_{4}$ molecules, as in $\mathrm{P}_{4}$, are recognisable. It should be added that a variety of arsenic (yellow arsenic) is formed as a sublimation product. It is cubic and presumably consists of $\mathrm{As}_{4}$ molecules, but structural data could not be obtained (Jung, 1926).

When additional $\mathrm{O}$ atoms are inserted in the first phase of $\mathrm{As}_{2} \mathrm{O}_{3}, \mathrm{AsO}_{2}$ is obtained. The As skeleton is somewhat different, but maintains the layers of the elemental As. The additional $\mathrm{O}$ atoms are placed close to the lone pairs, but only in alternate As atoms so that the coordination of arsenic varies from 3 to 4 .
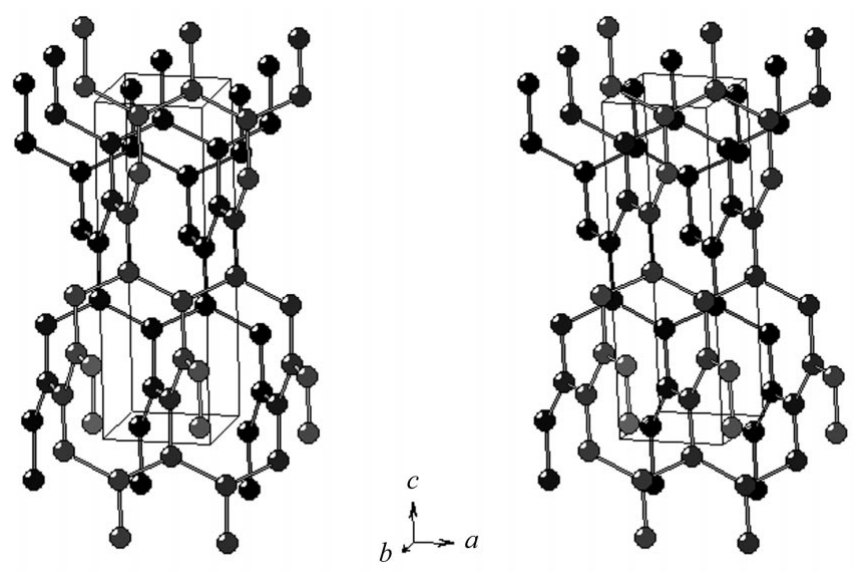

Figure 3

Stereopair showing the silicon partial structure of $\mathrm{HP}-\mathrm{SrSi}_{2}$. This array is similar to the third phase of $\mathrm{P}_{2} \mathrm{O}_{5}$.
The two phases of $\mathrm{As}_{2} \mathrm{O}_{5}$ are topologically related. The first, prepared under oxygen pressure (Jansen, 1978), has an As subarray similar to the $\mathrm{Si}$ array (pseudo-phosphorus) in the ambient pressure phase of $\mathrm{SrSi}_{2}$ (Evers, 1978) and is formed by a three-connected net of both eight- and four-membered rings. This net is represented in Fig. 5. The second phase is stable above $578 \mathrm{~K}$ (Jansen, 1979a) and presents an arsenic subarray topologically related to the room-temperature phase. The difference is that in this case there is an As1 atom which is four-connected and the second one, As2, six-connected. It should be noted that in both phases of $\mathrm{As}_{2} \mathrm{O}_{5}$, one As atom (As1) is coordinated by six $\mathrm{O}$ atoms whereas As2 is only tetracoordinated by four $\mathrm{O}$ atoms. This situation makes difficult the use of the principles applied to the other tetra-coordinated $X$ atoms. Nevertheless, the skeleton of a pseudo-phosphorus atom as that existing in the Zintl phase $\mathrm{SrSi}_{2}$ is observed in the oxides.

Antimony forms three oxides: $\mathrm{Sb}_{2} \mathrm{O}_{3}, \mathrm{SbO}_{2}$ and $\mathrm{Sb}_{2} \mathrm{O}_{5}$. $\mathrm{SbO}_{2}$ has one unique phase; the other two are stable in two phases. The first phase of $\mathrm{Sb}_{2} \mathrm{O}_{3}$ (Svensson, 1974) is formed by double chains of $\mathrm{Sb}$ atoms which are connected by additional interchain contacts. The final result is a band of zigzag puckered squares with the $\mathrm{O}$ atoms close to the midpoint of each square edge (see Fig. 6). In the second phase (Svensson, 1975), $\mathrm{Sb}_{4} \mathrm{O}_{6}$ forms a structure similar to $\mathrm{P}_{4} \mathrm{O}_{6}$ and $\mathrm{As}_{4} \mathrm{O}_{6}$ where $\mathrm{Sb}_{4}$ tetrahedra are recognisable.

The same skeleton $\left(\mathrm{Sb}_{4}\right)$ is formed in one of the phases of $\mathrm{Sb}_{4} \mathrm{O}_{10}$ (Dehlinger, 1927), whereas in the second phase of $\mathrm{Sb}_{2} \mathrm{O}_{5}$ (Jansen, 1979b) the Sb atoms form a network which is

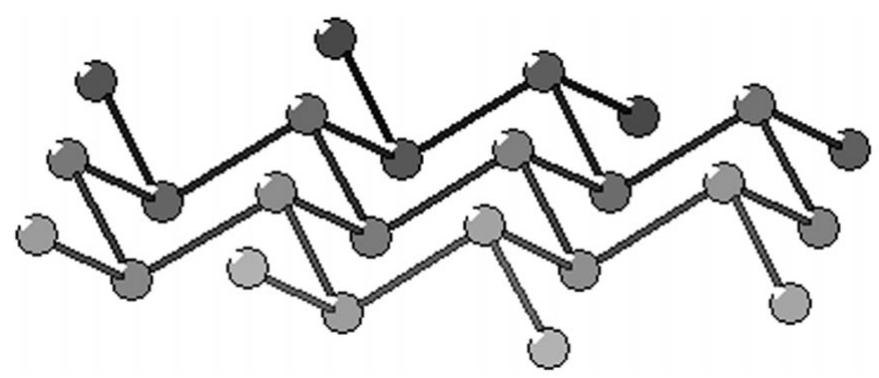

Figure 4

One layer of elemental As showing the chair conformation of the sixmembered rings.
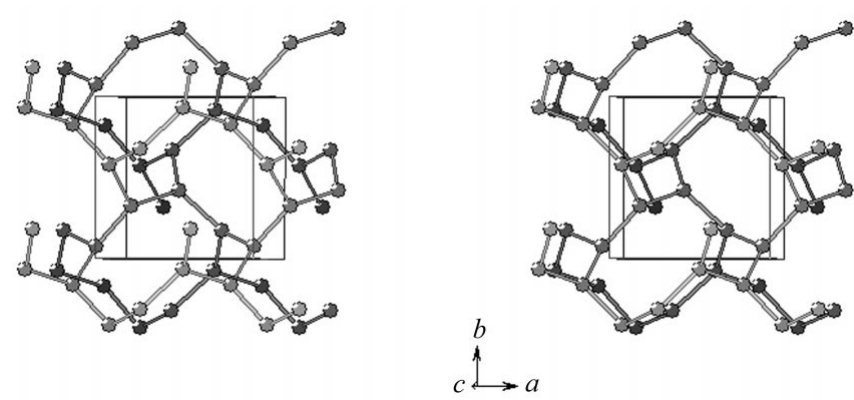

Figure 5

Stereopair showing the Si structure of the ambient pressure phase of $\mathrm{SrSi}_{2}$. The $\mathrm{Si}$ atoms form a three-connected net formed by squares and octagonal helices as in $\mathrm{As}_{2} \mathrm{O}_{5}$. 
close to the cubes present in the structure of $\mathrm{Bi}$ and in the HP phase of Sb. In this oxide all the Sb atoms appear octahedrally coordinated by six $\mathrm{O}$ atoms and the octahedra share corners in some directions and edges in other directions, as required by the stoichiometry $X_{2} \mathrm{O}_{5}$.

In $\mathrm{SbO}_{2}$ (Thornton, 1977) the $\mathrm{Sb}$ atoms show two types of coordination. The structure is represented in Fig. 7. It has layers of corner-connected $\mathrm{Sb}(\mathrm{O})_{6}$ octahedra intercalated by layers of irregular $\mathrm{Sb}(\mathrm{O})_{4}$ polyhedra, but owing to the lower $\mathrm{O}$ contents, these polyhedra share edges in one direction. The $\mathrm{Sb}$ substructure is formed by simple broken cubes, as seen in Fig. 7. This array is similar to that found in $\mathrm{Sb}_{2} \mathrm{O}_{5}$, which is also close to the Bi s.c. (simple cubic) structure.

The reported oxides of bismuth are $\mathrm{Bi}_{2} \mathrm{O}_{3}$ (stable in the varieties $\alpha, \beta, \gamma$ and $\delta$; Harwig, 1978) and $\mathrm{BiO}_{2}$ (Kumada et al., $1995)$. With regard to $\mathrm{Bi}_{2} \mathrm{O}_{3}$ the $\alpha$-phase contains very irregular cubes of bismuth, as in the element. The $\beta$ and $\delta$ varieties are HT (high-temperature) phases in which the Bi atoms form f.c.c. arrays. The $\gamma$ phase contains a very irregular array of $\mathrm{Bi}$ atoms in which connected tetrahedra can be identified. $\mathrm{In}_{\mathrm{BiO}}$ the metal atoms form an array similar to that of $\mathrm{SbO}_{2}$, which was discussed above.

From the Group 16 elements the following oxides have been reported: $\mathrm{SO}_{3}$ (asbestos-like), $\mathrm{S}_{3} \mathrm{O}_{9}, \mathrm{SeO}_{2}, \mathrm{Se}_{2} \mathrm{O}_{5}, \mathrm{Se}_{4} \mathrm{O}_{12}$, $\mathrm{TeO}_{2}, \mathrm{Te}_{2} \mathrm{O}_{5}$ and $\mathrm{TeO}_{3}$.

In $\mathrm{SO}_{3}$ (Westrik \& McGillavry, 1954), the $\mathrm{SO}_{4}$ tetrahedra share two corners to form infinite chains, where the $\mathrm{S}$ atoms form helices as they do in fibrous or plastic sulfur and also in sulfur at high pressure (30-60 Kb; Sclar et al., 1966). $\mathrm{S}_{3} \mathrm{O}_{9}$ consists of trimers in which the $\mathrm{S}$ atoms form triangles as in the $\mathrm{S}_{3}$ molecules (Chen et al., 2001).

In $\mathrm{SeO}_{2}$ (Stahl et al., 1992) the Se atoms form infinite chains ( $\mathrm{Se}-\mathrm{Se}-\mathrm{Se}$ angle of $106.38^{\circ}$ ), resembling the structure of $\alpha$ $\mathrm{Se}$. The $\mathrm{O}$ atoms are situated close to the midpoint of the $\mathrm{Se}-$ Se bonds and close to one of the lone pairs attached to the Se atom. $\mathrm{Se}_{2} \mathrm{O}_{5}$ (Zak, 1980) also contains infinite chains of selenium, but where the angles are of the order $96^{\circ}$. Here, the additional $\mathrm{O}$ atoms are situated close to other lone pairs of Se. This leads to alternating coordination numbers of three and four. $\mathrm{Se}_{4} \mathrm{O}_{12}$ is a tetramer. The Se atoms form squares which deviate from planarity as in the $\mathrm{S}_{4}$ molecule, as deduced from

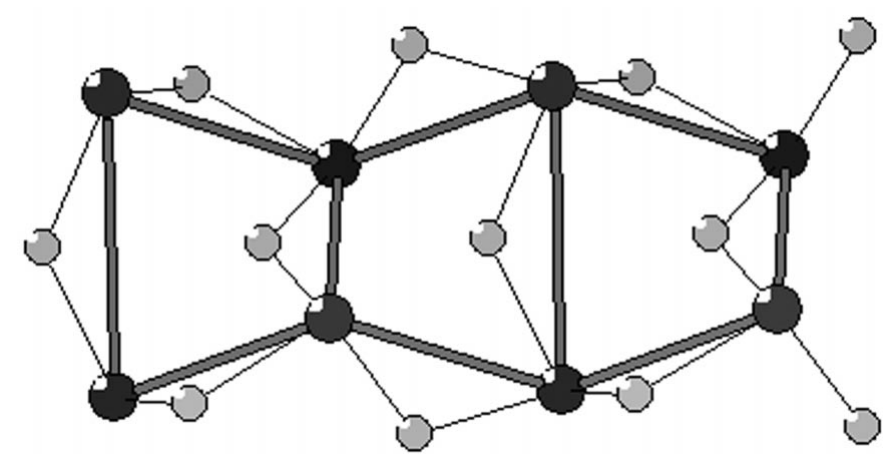

Figure 6

The structure of $\mathrm{Sb}_{2} \mathrm{O}_{3}$. Black circles: $\mathrm{Sb}$; grey circles: $\mathrm{O}$. The $\mathrm{Sb}$ atoms form puckered squares with the $\mathrm{O}$ atoms located close to the midpoint of the $\mathrm{Sb}-\mathrm{Sb}$ bonds. theoretical calculations (Chen et al., 2001). $\mathrm{Se}_{4}$ molecules have also been reported.

For $\mathrm{TeO}_{2}$ three phases were reported. The $\alpha$-phase, synthesized by fusion (Leciejewicz, 1961), has been included in the rutile group. Its cation array is of the $\gamma$-Sn type. However, the $\mathrm{Te}$ atom has only four $\mathrm{O}$ atoms in its first coordination sphere. These $\mathrm{O}$ atoms form a polyhedron similar to that appearing in the $\mathrm{SeO}_{2}$ structures discussed above. The HP $\gamma$-phase (Worlton \& Beyerlein, 1975) contains zigzag chains of Te atoms, forming angles of $76^{\circ}$. The Te atoms are tetra-coordinated by four $\mathrm{O}$ atoms in a way similar to that of the $\alpha$-phase. The third phase (the mineral tellurite) has been reported to be similar to the mineral brookite $\left(\mathrm{TiO}_{2}\right.$; Ito \& Sawada, 1939). The Te atoms have the same coordination polyhedron in the other phases. The structure is represented in Fig. 8. However, the best way of describing the Te substructure

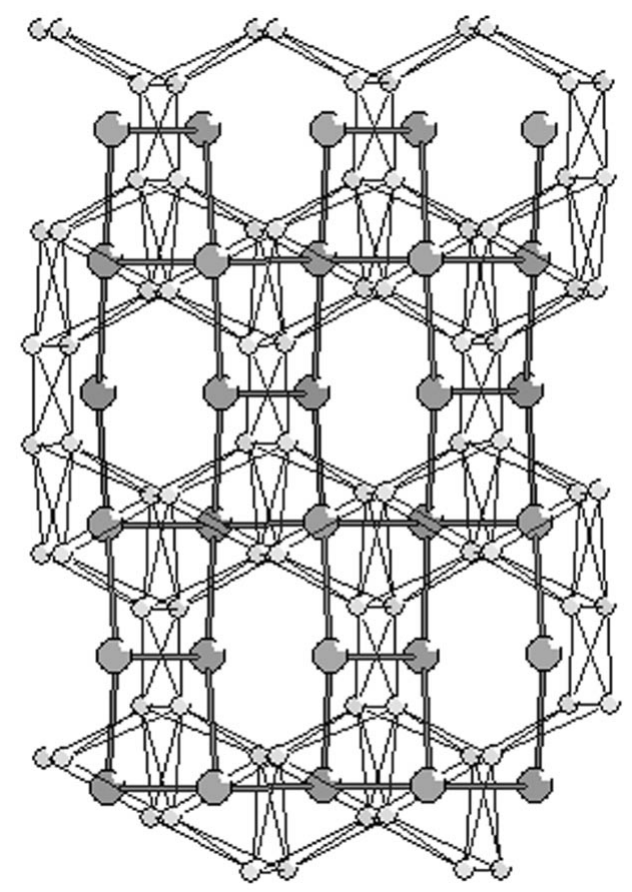

Figure 7

The structure of $\mathrm{Sb}_{2} \mathrm{O}_{4}$ projected on the $b c$ plane. Large circles: $\mathrm{Sb}$; small circles: $\mathrm{O}$.

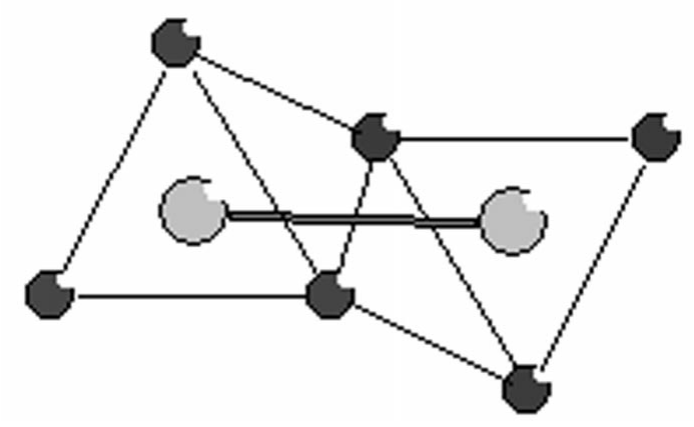

Figure 8

The structure of tellurite, III- $\mathrm{TeO}_{2}$. The drawing shows a $\mathrm{Te}_{2} \mathrm{O}_{4}$ unit in which the Te atoms form dumbbells as in the $\mathrm{S}_{2}$ molecules. The terminal $\mathrm{O}$ atoms are shared with adjacent $\mathrm{Te}_{2} \mathrm{O}_{4}$ units. 
is to consider the existence of molecules of $\mathrm{Te}_{2}$, as in $\mathrm{S}_{2}$ (Spencer et al., 2000). Two O atoms are situated midway between the two Te atoms as if they were to catch the four electrons forming the double bond. Another two $\mathrm{O}$ atoms are placed close to the expected position of the lone pairs. These $\mathrm{O}$ atoms, in turn, interact with adjacent $\mathrm{Te}_{2}$ molecules. Considering these latter interactions the array of titanium in brookite is obtained.

The structure of $\mathrm{Te}_{2} \mathrm{O}_{5}$ (Lindqvist \& Moret, 1973) can be related to that of $\mathrm{Sb}_{2} \mathrm{O}_{5}$. In this structure layers of hexa- and tetra-coordinated tellurium alternate, producing a cation array which cannot be related to any phase of the element.

In $\mathrm{TeO}_{3}$ the $\mathrm{Te}$ atoms are octahedrally coordinated by six $\mathrm{O}$ atoms, each $\mathrm{O}$ atom being common to two octahedra. Thus, the Te atoms form a primitive rhombohedral network $(\alpha=$ $86.22^{\circ}$ ) similar to that existing in HP (high-pressure) $\gamma$-Te and almost similar to the simple cubic structure of $\beta$-Po.

It is well known that III-V and II-VI compounds also reproduce the structures of the Group 14 (IVb) elements. This is the case for $\mathrm{BN}$, which crystallizes in both graphite- and diamond-like structures, or BP, which adopts the zinc blende structure. For this reason we have also included in Table 1 some of these compounds and their corresponding oxides which, as occurred with the binary oxides, also maintain the structure of their respective III-V or II-VI binary compounds. Thus, $\mathrm{BPO}_{4}$ (cristobalite-like structure) reproduces the zincblende network of BP. This compound also crystallizes with the quartz- and trydimite-like structures which have not been observed in BP, but which can be related to structures of the Group 14 elements. The same can be said of $\mathrm{AlPO}_{4}$ (quartz-
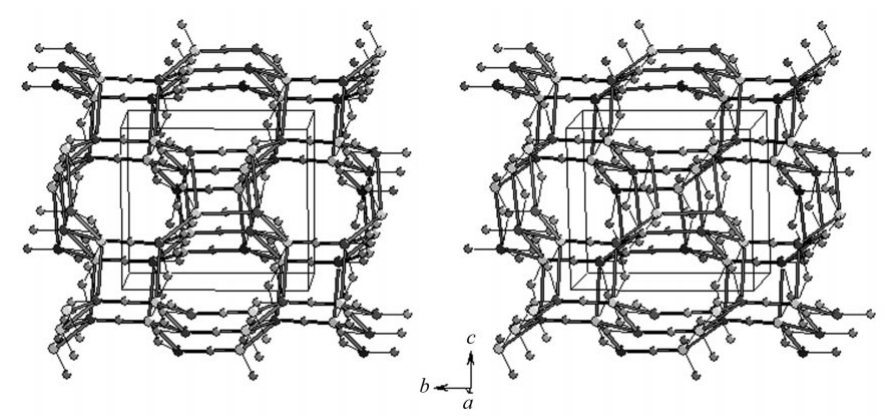

(a)
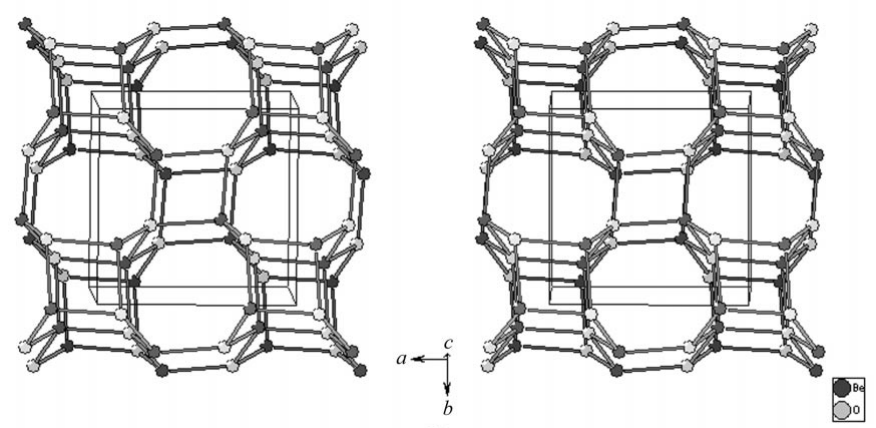

(b)

\section{Figure 9}

(a) Stereopair showing the $\mathrm{AlPO}_{4}$ skeleton in metavariscite, $\mathrm{AlPO}_{4} \cdot 2 \mathrm{H}_{2} \mathrm{O}$. The $\mathrm{P}$ and $\mathrm{Al}$ atoms are bonded by contacts to show its similarity with the structure of $\beta$ - $\mathrm{BeO}$. (b) The structure of $\beta$-BeO. like) which is related, as mentioned above, to $\mathrm{CrSi}_{2}$. We have also included dihydrates of $\mathrm{AlPO}_{4}$, i.e. the minerals variscite and metavariscite $\left(\mathrm{AlPO}_{4} \cdot 2 \mathrm{H}_{2} \mathrm{O}\right)$, because, even being quaternary compounds, the AlP subarrays are intimately related either to structures of the Group 14 or to plausible structures of this group. In metavariscite (Kniep \& Mootz, 1973) the AlP subarray forms a three-dimensional fourconnected net with octagons and squares (Fig. 9) This array is similar to the boron network in $\mathrm{CrB}_{4}$ and also presents similarities with the Al-Si array in paracelsian (Kniep, 1978). Moreover, this network is also identical to the structure of $\beta$ $\mathrm{BeO}$, a II-VI compound which is also represented in Fig. 9. Although no element of Group 14 presents this structure it is surprising that both a Zintl phase such as $\mathrm{CrB}_{4}$, in which the $\mathrm{B}$ atom could be structurally converted into a pseudo-carbon, as well as a II-VI binary oxide as in $\beta$ - $\mathrm{BeO}$ adopt this structure. In variscite (Kniep et al., 1977), the second variety of $\mathrm{AlPO}_{4} \cdot 2 \mathrm{H}_{2} \mathrm{O}$, the AlP subarray also forms a network composed of $\mathbf{4 . 8 ^ { 2 }}$ layers, which alternate in the third direction in such a way that squares of the upper layers lie on the octagons of lower layers. This network is very similar to a variety of silicon compounds at HP (110-160 Kb; Crain et al., 1994). In fact, in projection, both structures are identical. The differences appear only in the third dimension. Thus, whereas in variscite there are $\mathbf{4 . 8}^{\mathbf{2}}$ layers, in HP-Si the octagons and squares convert into octagonal and squares helices. Both structures are represented in Fig. 10. Finally, BeS, another IIVI compound with the diamond structure, preserves this
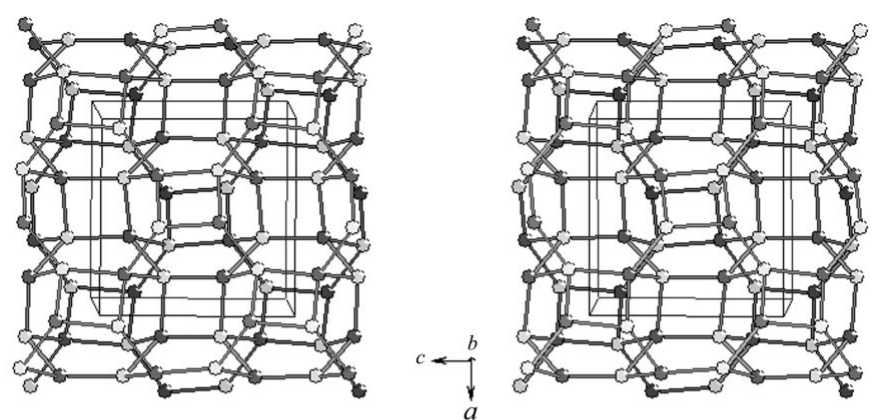

(a)
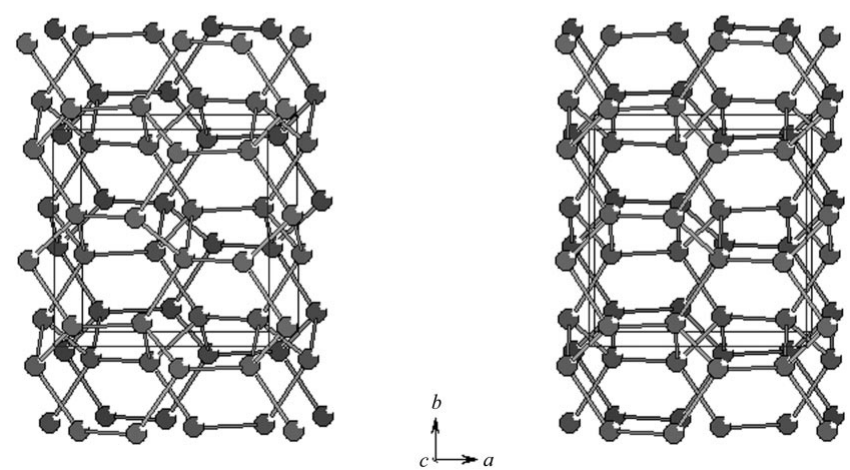

(b)

Figure 10

(a) Stereopair showing the four-connected AlP-skeleton in variscite, AlPO ${ }_{4} \cdot 2 \mathrm{H}_{2} \mathrm{O}$. (b) The structure of HP-Si to show the similarity with variscite. 
Table 2

The alkali metal aluminates.

$X=$ halogen.

\begin{tabular}{lll}
\hline Compounds & Space group & Al network \\
\hline $\mathrm{LiAlO}_{2}$ & $P 4_{1} 2_{1} 2, R \overline{3} m$ & Diamond-like \\
$\mathrm{LiAl}_{5} \mathrm{O}_{8}$ & $P m m n$ & Spinel $(\mathrm{Al})_{2}\left(\mathrm{LiAl}_{3}\right) \mathrm{O}_{8}$ \\
$\mathrm{Li}_{5} \mathrm{AlO}_{4}$ & $P 4_{3} 32$ & Discrete $\mathrm{AlO} \mathrm{O}_{4}^{5-}$ anions \\
$\mathrm{NaAlO}_{2}$ & $P n a 2_{1}, R \overline{3} m$ & Diamond-like \\
$\mathrm{NaAl}_{11} \mathrm{O}_{17}$ & $P 6_{3} / m m c$ & $\beta$-Alumina \\
$\mathrm{NaAl}_{23} \mathrm{O}_{35}$ & $P 6_{3} / m m c$ & $\beta$-Alumina \\
$\mathrm{Na}_{5} \mathrm{AlO}_{4}$ & $P b c a$ & Discrete $\mathrm{AlO}_{4}^{5-}$ anions \\
$\mathrm{Na}_{7} \mathrm{Al}_{3} \mathrm{O}_{8}$ & $P \overline{1}$ & Pseudo- $\mathrm{P}_{2} \mathrm{~S}$ \\
$\mathrm{Na}_{14} \mathrm{Al}_{4} \mathrm{O}_{13}$ & $P 2_{1} / c$ & Pseudo-S $X$ \\
$\mathrm{Na}_{17} \mathrm{Al}_{5} \mathrm{O}_{16}$ & $C m$ & Pseudo-S $X_{2}$ \\
$\mathrm{KAlO}_{2}$ & $P b c a$ & Diamond-like \\
$\mathrm{K}_{6} \mathrm{Al}_{2} \mathrm{O}_{6}$ & $C 2 / m$ & Pseudo-S $\left(\mathrm{S}_{2}\right.$ molecules) \\
$\mathrm{RbAlO}_{2}$ & $F d \overline{3} m$ & Diamond-like \\
$\mathrm{Rb}_{6} \mathrm{Al}_{2} \mathrm{O}_{6}$ & $C 2 / m$ & Pseudo-S $\left(\mathrm{S}_{2}\right.$ molecules) \\
$\mathrm{CsAlO}_{2}$ & $F d \overline{3} m$ & Diamond-like \\
$\mathrm{Cs}_{6} \mathrm{Al}_{2} \mathrm{O}_{6}$ & $P 2_{1} / c$ & Pseudo-S $\left(\mathrm{S}_{2}\right.$ molecules) \\
\hline
\end{tabular}

network when it forms the oxide $\mathrm{BeSO}_{4}$, as occurs with $\mathrm{ZnS}$ and $\mathrm{HT}_{\mathrm{ZnSO}_{4}}$ (Vegas \& Jansen, 2002).

As seen, the similarity between the elemental structures and those of the oxides is almost complete. As is well known, the structures of the main-group elements can be understood in the light of the $(8-N)$ rule. They form $(8-N)$ two-center, two-electrons bonds, the non-bonding electrons remaining as lone pairs. Consequently, it seems reasonable to think of the structures as oxides, just as if the $\mathrm{O}$ atoms had occupied positions close to the regions of maximal electron density, in the structure of the elements, such as the bonding pairs and the lone pairs. These regions of maximal electron density have been observed in $\mathrm{S}_{8}$ molecules in an electron density study (Coppens et al., 1977). If this were so, the tetrahedral coordination of the $X$ atoms would be justified because in most of these elemental structures the number of bonds and lone pairs is always four. This is particularly true in the compounds with the highest oxidation state, such as $X_{2} \mathrm{O}_{5}(X=\mathrm{P}, \mathrm{As}, \mathrm{Sb}), X_{3}$ $(X=\mathrm{S}, \mathrm{Se})$ and $X_{2} \mathrm{O}_{7}(X=$ halogen $)$.

\subsection{Alkali metal aluminates}

All the alkali metal aluminates are collected in Table 2. Their structures will be interpreted in the light of the ZintlKlemm concept as if the alkali metal atoms would donate electrons to the $\mathrm{Al}$ atoms, converting them into main-group pseudo-atoms. The skeleta formed by the $\mathrm{Al}$ atoms will then be compared either with the structures of the $p$-block elements or with those of pseudo-atoms formed in Zintl phases.

We will begin with the compounds of stoichiometry $M \mathrm{AlO}_{2}$ ( $M=\mathrm{Li}, \mathrm{Na}, \mathrm{K}, \mathrm{Rb}, \mathrm{Cs}$; Marezio, 1965; Kaduk \& Pei, 1995; Husheer et al., 1999; Langlet, 1964). All these compounds crystallize as stuffed cristobalites in which the Al array adopts the structure of elemental Si (diamond-like). The compounds can be thought of as if the valence electrons of the alkali metal would have been transferred to the $\mathrm{Al}$ atoms, transforming it into a pseudo-silicon, thus forming four tetrahedral bonds with the four neighbours. If we consider the existence of these bonds, the $\mathrm{O}$ atoms would be inserted close to the midpoint between the two Al atoms just as if they would play the role of an electron pair forming the hypothetical $\mathrm{Al}-\mathrm{Al}$ bonds. Two of these compounds, $\mathrm{LiAlO}_{2}$ (Marezio \& Remeika, 1966) and $\mathrm{NaAlO}_{2}$ (Reid \& Ringwood, 1968), transform at high pressures into the $\alpha-\mathrm{NaFeO}_{2}$-type structure in which $\mathrm{Al}^{3+}$ cations are inserted into the octahedral holes of an f.c.c. array of $\mathrm{O}$ atoms. In this structure the $\mathrm{Al}$ atoms form $\mathbf{3}^{\mathbf{6}}$ layers with an $\mathrm{Al}-\mathrm{Al}$ distance of $2.86 \AA$, just the shortest distance in elemental aluminium as it occurs in other Al oxides (RamosGallardo \& Vegas, 1995; Isea et al., 1998; Vegas, 2000).

$\mathrm{Li}_{5} \mathrm{AlO}_{4}$ and $\mathrm{Na}_{5} \mathrm{AlO}_{4}$ present the same structural features. They are composed of $M^{+}$cations and isolated $\mathrm{AlO}_{4}^{5-}$ anions, similar to $\mathrm{SiO}_{4}^{4-}, \mathrm{PO}_{4}^{3-}, \mathrm{SO}_{4}^{2-}$ and $\mathrm{ClO}_{4}^{-}$anions. All of these are isoelectronic and can be interpreted as if the $X$ central atom had adopted a noble gas configuration, with eight electrons in the outer valence shell. The eight electrons would be arranged in four pairs at the corners of a tetrahedron, which are the positions of the four $\mathrm{O}$ atoms. Also here, the ZintlKlemm concept is maintained, with a formal transfer of five electrons from the alkali metal atoms to the $\mathrm{Al}$ atom.

The compounds $M_{6} \mathrm{Al}_{2} \mathrm{O}_{6}(M=\mathrm{K}, \mathrm{Rb}, \mathrm{Cs})$ have the same structural principles. Those of $\mathrm{K}$ and $\mathrm{Rb}$ are isostructural. They are formed by $\mathrm{Al}_{2} \mathrm{O}_{6}^{6-}$ anions, which consist of two $\mathrm{AlO}_{4}$ tetrahedra joined by a common edge, as seen in Fig. 11. Considering the $\mathrm{Al}$ subarray it can be said that the anion is formed by $(\mathrm{Al}=\mathrm{Al})^{6-}$ molecules, as if the six $M$ atoms had donated six electrons to the two $\mathrm{Al}$ atoms, converting them into two pseudo-sulfur atoms which adopt the structure of a $\mathrm{S}_{2}$ molecule. In this molecule, the $S$ atoms would be connected by a double bond $(\mathrm{S}=\mathrm{S})$, with two additional lone pairs on each $\mathrm{S}$ atom. Four $\mathrm{O}$ atoms would be situated on the lone pairs with two additional ones catching the four electrons involved in the $\mathrm{Al}=\mathrm{Al}$ double bond. The $\mathrm{S}_{2}$ molecule has been observed in the gas phase (Spencer et al., 2000), but it also exists as a pseudo-atom in the Zintl compound $\mathrm{Li}_{2} \mathrm{Si}$ where the electrons from lithium convert the Si atoms in pseudo-sulfur in the form of $(\mathrm{Si}=\mathrm{Si})^{4-}$ anions (Axel et al., 1990). We have seen how these $X=X$ molecules could also exist in $\mathrm{TeO}_{2}$.

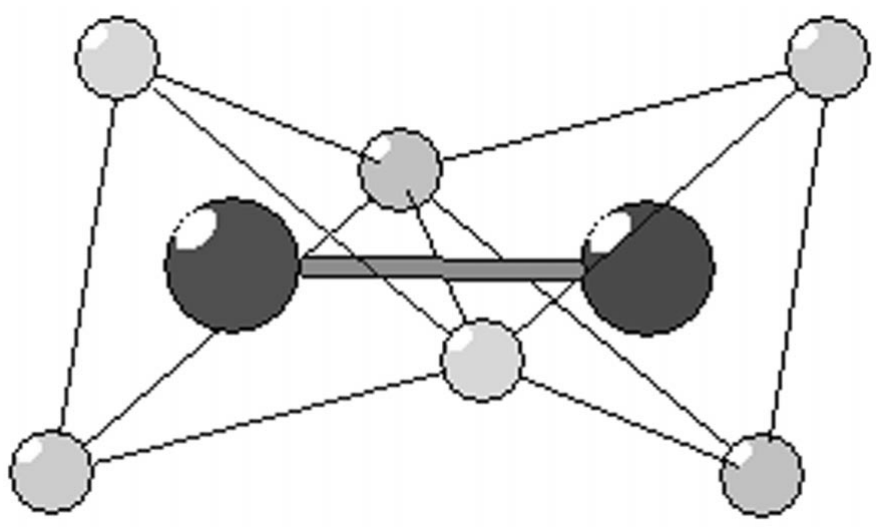

Figure 11

The structure of the $\left(\mathrm{Al}_{2} \mathrm{O}_{6}\right)^{6-}$ anion in $\mathrm{K}_{6} \mathrm{Al}_{2} \mathrm{O}_{6}$. It is formed by two edge-sharing tetrahedra in which the $\mathrm{Al}$ atoms form dumbbells as in the $\mathrm{S}_{2}$ molecule. 
Table 3

The alkaline-earth aluminates.

\begin{tabular}{lll}
\hline Compounds & Space group & Al network \\
\hline $\mathrm{BeAl}_{2} \mathrm{O}_{4}$ & $P n m a$ & $\mathrm{Ni}_{2} \mathrm{In}$ \\
$\mathrm{MgAl}_{26} \mathrm{O}_{40}$ & $P 2 / m$ & $\beta$-Alumina \\
$\mathrm{MgAl}_{2} \mathrm{O}_{4}$ & $F \overline{4} 3 m$ & Spinel $\left(\mathrm{MgCu}_{2}\right)$ \\
$\mathrm{CaO}\left(\mathrm{Al}_{2} \mathrm{O}_{3}\right)_{6}$ & $P 6_{3} / m m c$ & $\beta$-Alumina \\
$\mathrm{CaAl} \mathrm{O}_{4}$ & $C 2 / c$ & \\
$\mathrm{CaAl}_{2} \mathrm{O}_{4}$ & $P 2_{1} / n, P 2_{1} / c$ & Diamond hexagonal $\mathrm{HP}-$ hexagons and \\
& & squares \\
$\mathrm{Ca}_{2} \mathrm{Al}_{2} \mathrm{O}_{5}$ & $I 2 m b$ & Brownmillerite $\left(\mathrm{Sb}_{2} \mathrm{O}_{4}\right.$ and $\left.\mathrm{Sb}_{2} \mathrm{O}_{5}\right)$ \\
$\mathrm{Ca}_{4} \mathrm{Al}_{6} \mathrm{O}_{13}$ & $I \overline{4} 3 m$ & Pseudo-Si (sodalite) \\
$\mathrm{Ca}_{5} \mathrm{Al}_{6} \mathrm{O}_{14}$ & $C m c 2_{1}$ & As ${ }_{2} \mathrm{Ge}$ \\
$\mathrm{Ca}_{9} \mathrm{Al}_{6} \mathrm{O}_{18}$ & $P a \overline{3}$ & Pseudo-S $\left(\mathrm{S}_{6}\right.$ molecules $)$ \\
$\mathrm{Ca}_{12} \mathrm{Al}_{14} \mathrm{O}_{33}$ & $I \overline{4} 3 d$ & Pseudo-P $\mathrm{Si}_{3}$ \\
$\left.\mathrm{SrO}_{2} \mathrm{Al}_{2} \mathrm{O}_{3}\right)_{6}$ & $P 6_{3} / m m c$ & $\beta$-Alumina \\
$\mathrm{SrAl}_{2} \mathrm{O}_{4}$ & $P 2_{1}$ & Diamond hexagonal \\
$\mathrm{SrAl}_{4} \mathrm{O}_{7}$ & $C 2 / c, C m m a$ & \\
$\mathrm{Sr}_{4} \mathrm{Al}_{14} \mathrm{O}_{25}$ & $P m m a$ & \\
$\mathrm{Sr}_{7} \mathrm{Al}_{12} \mathrm{O}_{25}$ & $P 3$ & \\
$\mathrm{Sr}_{9} \mathrm{Al}_{6} \mathrm{O}_{18}$ & $P a \overline{3}$ & Pseudo-Si \\
$\mathrm{BaAl}_{2} \mathrm{O}_{4}$ & $P 6_{3} 22$ & Pseudo-S $\left(\mathrm{S}_{6}\right.$ molecules $)$ \\
$\mathrm{Ba}_{3} \mathrm{Al}_{2} \mathrm{O}_{6}$ & $P 2_{1} 2_{1} 2_{1}, P a \overline{3}$ & Diamond hexagonal \\
$\mathrm{Ba}_{17} \mathrm{Al}_{3} \mathrm{O}_{7}$ & $P 4_{2} / m c m$ & Pseudo-S $\left(\mathrm{S}_{12}\right.$ molecule) \\
\end{tabular}

In $\mathrm{Na}_{7} \mathrm{Al}_{3} \mathrm{O}_{8}$ all the $\mathrm{Al}$ atoms appear in the tetrahedral coordination. The $\mathrm{Al}$ network is represented in Fig. 12 and consists of infinite chains of alternate six and four rings, in which two $\mathrm{Al}$ atoms are three-connected and one $\mathrm{Al}$ atom is two-connected. Even if this skeleton does not correspond to any main-group element nor to any Zintl polyanion, its connectivity conforms to the Zintl-Klemm concept if we assume that two $\mathrm{Al}$ atoms are converted into pseudo-phosphorus (transfer of two electrons per atom) and one into pseudo-sulfur (transfer of three electrons), giving rise to two three-connected atoms (pseudo-phosphorus) and one twoconnected atom (pseudo-sulfur). As seen in other oxides, $\mathrm{O}$ atoms are located on bonding pairs and lone-pair regions thus producing a tetrahedral coordination of the $\mathrm{Al}$ atoms.

Another two compounds which conform to this concept are $\mathrm{Na}_{14} \mathrm{Al}_{4} \mathrm{O}_{13}$ and $\mathrm{Na}_{17} \mathrm{Al}_{5} \mathrm{O}_{16}$. The former contains isolated $\left(\mathrm{Al}_{4} \mathrm{O}_{13}\right)^{14-}$ polyanions, such as those represented in Fig. 13. The $\mathrm{Al}$ subarray consists of four $\mathrm{Al}$ atoms which form $\mathrm{Al}-$ $\mathrm{Al}-\mathrm{Al}$ angles of $114^{\circ}$ and is also consistent with the Zintl-

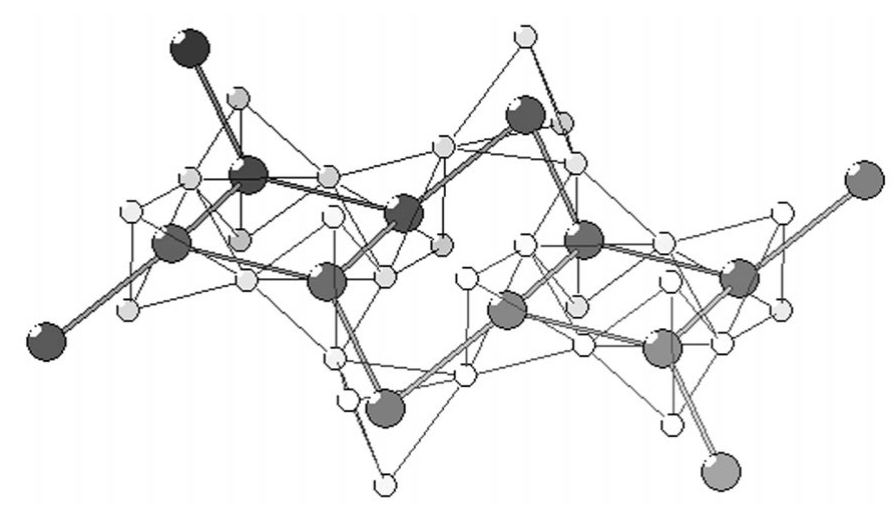

Figure 12

The tetrahedral $\mathrm{Al}$ network in $\mathrm{Na}_{7} \mathrm{Al}_{3} \mathrm{O}_{8}$, showing the pseudophosphorus and pseudo-sulfur atoms.
Klemm concept. The two central $\mathrm{Al}$ atoms are two-connected as if they were pseudo-sulfur and two terminal ones are oneconnected as if they were pseudo-halogen. To achieve this, a total of $6+8$ electrons need to be transferred, which is just the number of $\mathrm{Na}^{+}$cations forming the structure. It is worth mentioning that the same polyanion is formed in the Zintl phase $\mathrm{Ba}_{3} \mathrm{P}_{4}$ (von Schnering et al., 1984), where two $\mathrm{P}$ atoms convert into pseudo-sulfur and two into pseudo-chlorine with a total transfer of $2+4$ electrons.

The same can be said of $\mathrm{Na}_{17} \mathrm{Al}_{5} \mathrm{O}_{16}$. The structure contains $\left(\mathrm{Al}_{5} \mathrm{O}_{16}\right)^{17-}$ polyanions formed by five corner-sharing $\mathrm{Al}(\mathrm{O})_{4}$ tetrahedra in which the $\mathrm{Al}$ atoms adopt a zigzag conformation with angles ranging from 113 to $114^{\circ}$. This polyaluminate anion is represented in Fig. 14 and can also be understood in the light of the Zintl-Klemm concept. With a formal transfer of nine electrons, the three central atoms of Fig. 14 are converted into pseudo-sulfur and by a formal transfer of eight electrons the two terminal $\mathrm{Al}$ atoms convert into pseudochlorine (the total number of transferred electrons is 17). As in the other polyaluminates, $\mathrm{O}$ atoms are also located at the lone pairs and bonding pairs. Surprisingly, this $\mathrm{Al}$-array is just that formed by the $\mathrm{S}$ atoms in the Zintl phase $\mathrm{K}_{2} \mathrm{~S}_{5}$ (Kelly \& Woodward, 1976), where two $S$ atoms behave as pseudochlorine by the transfer of two electrons.

Finally, in $\mathrm{LiAl}_{5} \mathrm{O}_{8}$ with the spinel structure, the $\mathrm{Al}$ atoms present two types of coordination spheres. The $\mathrm{Li}$ atoms and the three $\mathrm{Al}$ atoms are located at the octahedral sites, whereas two $\mathrm{Al}$ atoms occupy the tetrahedral interstices. This structure can be considered as a filled variant of $\gamma-\mathrm{Al}_{2} \mathrm{O}_{3}$, which is a

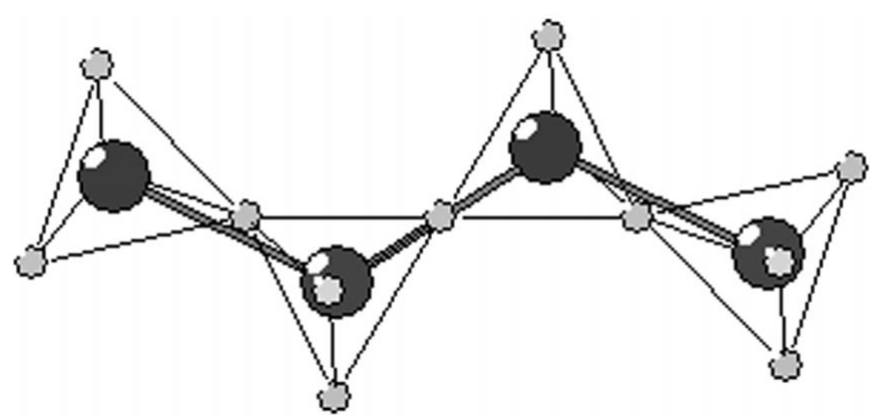

Figure 13

The $\left(\mathrm{Al}_{4} \mathrm{O}_{13}\right)^{14-}$ anion in $\mathrm{Na}_{14} \mathrm{Al}_{4} \mathrm{O}_{13}$. The two central $\mathrm{Al}$ atoms are pseudo-sulfur and the two terminal are pseudo-halogen. The Al-array is similar to the $\mathrm{P}$-array in $\mathrm{Ba}_{3} \mathrm{P}_{4}$.

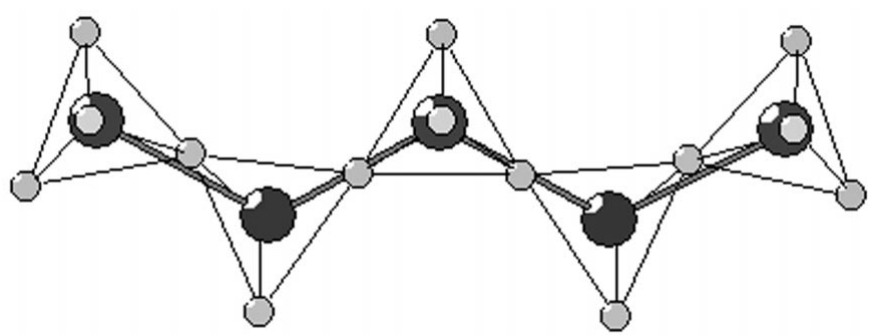

Figure 14

The $\left(\mathrm{Al}_{5} \mathrm{O}_{16}\right)^{17-}$ anion in $\mathrm{Na}_{17} \mathrm{Al}_{5} \mathrm{O}_{16}$. It is formed by discrete units of five corner-connected tetrahedra. It consists of three pseudo-sulfur and two pseudo-halogens as the S-array in $\mathrm{K}_{2} \mathrm{~S}_{5}$. 
defect spinel. As has been reported for spinel itself $\left(\mathrm{MgAl}_{2} \mathrm{O}_{4}\right.$; Isea et al., 1998; Vegas, 2000), the octahedral $\mathrm{Al}$ atoms form an array which is one half of an f.c.c. array in which the $\mathrm{Al}-\mathrm{Al}$ distance is $2.86 \AA$, just the value of the same distance in $\mathrm{Al}$ metal. Consequently, the unit-cell parameter of the spinel structure becomes twice the unit cell of f.c.c.-Al. In $\mathrm{LiAl}_{5} \mathrm{O}_{8}$, however, owing to the partial insertion of $\mathrm{Li}$, the unit-cell parameter is somewhat contracted (compare the values of $7.903 \AA$ in $\mathrm{LiAl}_{5} \mathrm{O}_{8}$ with $4.04 \AA$ in aluminium metal). It seems that a small proportion of the alkali metal in the aluminates does not produce the effect of transforming aluminium into other main group element structures unless we admit that aluminium has an amphoteric character and that the three $\mathrm{Al}$ atoms at the octahedral sites, together with the $\mathrm{Li}$ atom, convert the two tetrahedral $\mathrm{Al}$ atoms into a pseudo-argon, giving rise to the existence of $\mathrm{AlO}_{4}^{5-}$ anions. This was discussed above when we described the structures of the $M_{5} \mathrm{AlO}_{4}$ compounds. In this case, the spinel could be formulated as $\mathrm{LiAl}_{3}\left(\mathrm{AlO}_{4}\right)_{2}$.

What has been discussed for the spinel structure is also applicable to the two $\beta$-alumina structures $\mathrm{NaAl}_{11} \mathrm{O}_{17}$ and $\mathrm{NaAl}_{23} \mathrm{O}_{35}$. Here the $\mathrm{Al}$ atoms dominate the structures owing to the small amounts of $\mathrm{Na}$ taking part in the compounds. This type of Al array has previously been discussed (RamosGallardo \& Vegas, 1996). As occurs with other skeleta in which $\mathrm{Al}$ is hexa-coordinated, the $\mathrm{Al}^{3+}$ cations reproduce the topology and distances of elemental $\mathrm{Al}$.

\subsection{Alkaline-earth aluminates}

The alkaline-earth aluminates are collected in Table 3 . $\mathrm{MgAl}_{26} \mathrm{O}_{40}, \mathrm{CaO}\left(\mathrm{Al}_{2} \mathrm{O}_{3}\right)_{6}$ and $\mathrm{SrO}\left(\mathrm{Al}_{2} \mathrm{O}_{3}\right)_{6}$ have the structure of $\beta$-alumina, which has been described above.

$\mathrm{BeAl}_{2} \mathrm{O}_{4}$ (crysoberyl; Pilati et al., 1993) belongs to the olivine-group structures. In it, the $\mathrm{Al}$ atoms are octahedrally coordinated and the $\mathrm{Be}$ atoms are at the center of the $\mathrm{O}_{4}$ tetrahedra. The cation subarray, as in olivine, is of the $\mathrm{Ni}_{2} \mathrm{In}$ type (O'Keeffe \& Hyde, 1985), and the Al subarray can be described as fragments of the f.c.c. aluminium structure (Vegas et al., 1991). As in other aluminates containing $\mathrm{Al}^{3+}$ cations, the $\mathrm{Al}-\mathrm{Al}$ distances $(2.737 \times 2,2.907 \times 2$, mean value $2.82 \AA)$ reproduce those of the pure metal $(2.86 \AA$; Isea et al., 1998). This compound could then be formally formulated as composed of formal $\mathrm{Al}^{3+}$ cations and $\mathrm{BeO}_{4}^{6-}$ anions.

$\mathrm{MgAl}_{2} \mathrm{O}_{4}$, the mineral spinel, has also been described above, when we discussed the structure of $\mathrm{LiAl}_{5} \mathrm{O}_{8}$. There, we supposed the existence of $\mathrm{AlO}_{4}^{5-}$ anions, but if we apply the same principles here we must assume the existence of $\mathrm{MgO}_{4}^{6-}$ anions which could justify the existence of a tetrahedrally cordinated $\mathrm{Mg}^{2+}$ cation. However, this interpretation does not seem plausible and probably the best way of understanding this cation array should be to consider the $\mathrm{MgAl}_{2}$ subarray as a possible high-pressure phase of the $\mathrm{MgAl}_{2}$ alloy. This plausible alloy would be a Laves phase similar to the analogous $\mathrm{CaAl}_{2}$. All this discussion mentions is the difficulty of interpreting all the structural features of the spinel structure, especially when we take into account that the high-pressure phase of $\mathrm{Si}_{3} \mathrm{~N}_{4}$ also adopts this type of structure. In the nitride the Si subnet has the structure of a Laves phase. Is this array typical of a main group element? In this sense, must we interpret the $\mathrm{MgAl}_{2}$ subarray as if $\mathrm{Mg}$ donates two electrons to the two $\mathrm{Al}$ atoms converting them into pseudo-silicon? It should be pointed out that the truncated tetrahedra which are the basis of the Alskeleton in the Laves phases also appear as components of the Samson polyhedra in Zintl phases as $\mathrm{K}_{49} \mathrm{Tl}_{108}$ (Eisenmann \& Cordier, 1996).

Another compound, listed in Table 3, which is difficult to interpret is $\mathrm{Ba}_{17} \mathrm{Al}_{3} \mathrm{O}_{7}$ (Rohr \& George, 1995). The oxygen content here is not enough to accept all the electrons from the $\mathrm{Ba}$ atoms. There are two crystallographically independent $\mathrm{Al}$ atoms, one is not coordinated by $\mathrm{O}$ atoms but only by $\mathrm{Ba}$ atoms, forming a sort of alloy. The second $\mathrm{Al}$ atom forms groups of $\mathrm{Al}_{2} \mathrm{O}_{7}^{8-}$, which consist of two $\mathrm{Al}(\mathrm{O})_{4}$ tetrahedra sharing a corner. It can be interpreted as if part of the $\mathrm{Ba}$ electrons were transferred to the two $\mathrm{Al}$ atoms $\left(4 \mathrm{e}^{-}\right.$per atom) giving rise to a pseudo-halogen molecule which forms an $X_{2} \mathrm{O}_{7}$ group as it does with $\mathrm{Cl}_{2} \mathrm{O}_{7}$.

The structures of the remaining compounds can be satisfactorily explained by applying the Zintl-Klemm concept. Thus, $M_{\mathrm{Al}_{2} \mathrm{O}_{4}}(M=\mathrm{Ca}$, Sr, Ba), even crystallizing in three different space groups, have the same structure. The $\mathrm{Al}$ atoms form four-connected nets similar to wurtzite or hexagonal silicon (Jennings \& Richman, 1976). This can be achieved by assuming that the two valence electrons of the $\mathrm{AE}$ atom are transferred to the $\mathrm{Al}$ atoms converting them into pseudosilicon. The $\mathrm{O}$ atoms would be located in the vicinity of the midpoint of each $\mathrm{Al}-\mathrm{Al}$ bond. One of these compounds, $\mathrm{CaAl}_{2} \mathrm{O}_{4}$, has an additional high-pressure phase with a different structure (Ito et al., 1980). The Al subarray is also four-connected but instead of being formed only by sixmembered rings, as in the silicon-like network, it is formed by octagons, squares and hexagons which are arranged as the $\mathrm{P}$ and $\mathrm{Al}$ atoms in variscite, $\mathrm{AlPO}_{4} \cdot 2 \mathrm{H}_{2} \mathrm{O}$ (Kniep, 1978), as has been discussed above. It is surprising that the pseudo-silicon atoms in $\mathrm{CaAl}_{2} \mathrm{O}_{4}$ adopts the same structure as either $\mathrm{Si}$ itself or an III-V array, as in AlP.

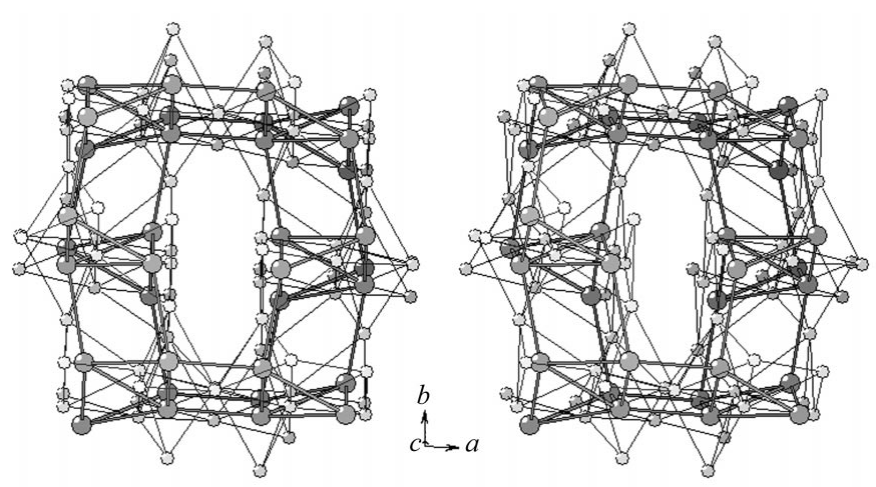

Figure 15

Stereopair showing the tetrahedral skeleton in $\mathrm{CaAl}_{4} \mathrm{O}_{7}$ at normal pressure. The $\mathrm{Al}-\mathrm{Al}$ contacts are drawn to show the five-connectivity of the $\mathrm{Al}$ atoms. The $\mathrm{O}$ atoms lying at the center of $\mathrm{Al}_{3}$ triangles are also seen. 
$\mathrm{CaAl}_{4} \mathrm{O}_{7}$ and $\mathrm{SrAl}_{4} \mathrm{O}_{7}$ are also isostructural (Boyko \& Wisnyl, 1958; see Table 3) with four formulae in the unit cell. In these compounds, all the $\mathrm{Al}$ atoms are tetrahedrally coordinated, with all $\mathrm{O}_{4}$ tetrahedra sharing corners. The structure is represented in Fig. 15. Looking at the $\mathrm{Al}$ array, it appears that half of the $\mathrm{Al}$ atoms (the eight Al1 atoms) are fiveconnected, whereas the other half (the eight $\mathrm{Al} 2$ atoms) are six-connected. Since calcium can only transfer eight $\mathrm{e}^{-}$, not all the $\mathrm{Al}$ atoms can be converted into pseudo-elements of the main group. This is the reason why, in this compound, the $\mathrm{Al}$ atoms show a higher and unusual connectivity which could be explained looking at the location of the $\mathrm{O}$ atoms. In the environment of $\mathrm{All}$, we see that three $\mathrm{O}$ atoms are situated close to the midpoint of three $\mathrm{Al}-\mathrm{Al}$ contacts, as if the three valence electrons of aluminium would have formed three directed, two-center, two-electron bonds. It is clear that the other two contacts do not originate from this type of bond because the central $\mathrm{Al}$ atom would have ten electrons, thus violating the octet rule. Therefore, the two remaining bonds

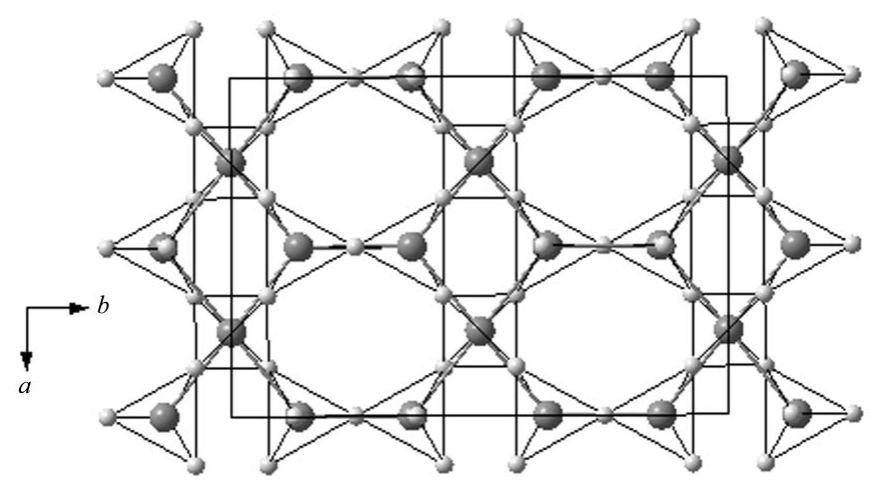

Figure 16

One layer of $\mathrm{Al}(\mathrm{O})_{4}$ tetrahedra in the high-pressure phase of $\mathrm{SrAl}_{4} \mathrm{O}_{7}$. The $\mathrm{Al}-\mathrm{Al}$ contacts show the four- and three-connectivity of the net.

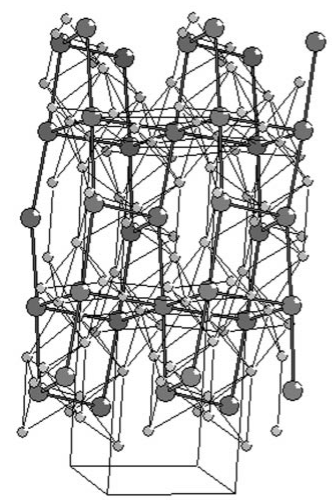

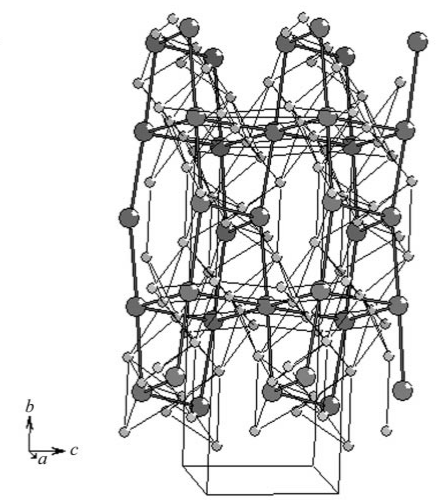

(a)

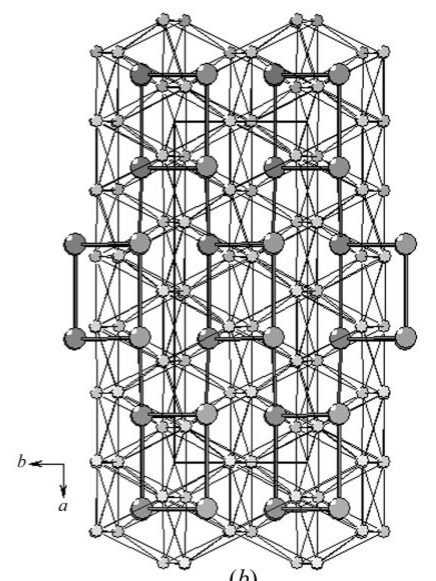

(b)
Figure 17

(a) Stereopair of the structure of the brownmillerite $\mathrm{Ca}_{2} \mathrm{Al}_{2} \mathrm{O}_{5}$. The $\mathrm{Al}-\mathrm{Al}$ contacts are drawn to show the similarity with the cubes of elemental $\mathrm{Bi}$. (b) The structure of $\mathrm{Sb}_{2} \mathrm{O}_{5}$ to show its similarity with $(a)$. are formed with two $\mathrm{Al}$ atoms belonging to a triangle which has only one $\mathrm{O}$ atom at its center, just as if the $\mathrm{Al}_{3}$ triangle corresponded to a three-center, two-electron bond. These two electrons would complete the octet of the central $\mathrm{Al}$ atom. In the case of $\mathrm{Al} 2$, which is six-connected, the $\mathrm{Al}-\mathrm{Al}$ bonding scheme can be explained in the same way. Here, there are two $\mathrm{Al}-\mathrm{Al}$ contacts which have the $\mathrm{O}$ atom midway between them. This seems to indicate that Al2 has used two valence electrons to form these two-center, two-electron bonds. The remaining four contacts take place with four $\mathrm{Al}$ atoms belonging to two different $\mathrm{Al}_{3}$ triangles than those described above. In this way the Al2 atoms also complete their octet. Thus there are eight electrons from calcium plus eight electrons from $\mathrm{Al} 2$ which are involved in these three-center, twoelectron bonds. This would lead to eight bonding pairs, which is just the number of such $\mathrm{O}(\mathrm{Al})_{3}$ triangles in the unit cell.

$\mathrm{SrAl}_{4} \mathrm{O}_{7}$ (Machida et al., 1982) has a second phase, which is synthesized at high pressures. In this phase there are three crystallographically independent $\mathrm{Al}$ atoms. Of these one (four atoms in the cell) is hexa-coordinated and the other two (12 atoms in the cell) are tetra-coordinated. These 12 atoms form planar nets composed of hexagons and squares in which threeand four-connected $\mathrm{Al}$ atoms coexist. This layer is represented in Fig. 16 and can also be interpreted by means of the ZintlKlemm concept as if the $\mathrm{Ca}$ atoms and the hexa-coordinated $\mathrm{Al}$ atoms would donate electrons to the tetrahedrally coordinated $\mathrm{Al}$ atoms, converting them into pseudo-silicon and pseudo-phosphorus. As seen in Fig. 16, the $\mathrm{O}$ atoms are located midway between the $\mathrm{Al}-\mathrm{Al}$ contacts and also on the lone pair existing on the pseudo-phosphorus atom. These layers are held together by the $\mathrm{Al}^{3+}$ (hexa-coordinated) cations.

The next compound to be discussed is $\mathrm{Ca}_{2} \mathrm{Al}_{2} \mathrm{O}_{5}$ (Kahlenberg et al., 2000). It is a high-pressure phase and has a brownmillerite-type structure. Brownmillerite has traditionally been described as an O-defect perovskite in which layers of corner-sharing $\mathrm{Al}(\mathrm{O})_{6}$ octahedra alternate with layers of $\mathrm{Al}(\mathrm{O})_{4}$ tetrahedra. These tetrahedra share two corners with the upper and lower octahedral layers and one additional corner with one neighbouring tetrahedron within the same layer. It is well known that the cation array in perovskites is of the $\mathrm{CsCl}$ type. Consequently, in brownmillerite the $\mathrm{CaAl}$ subarray has a similar structure but which is distorted, in principle, owing to the lower $\mathrm{O}$ contents and by the need to fit both the octahedral and tetrahedral geometries. An alternative description of this structure arises if we apply the Zintl-Klemm concept. By assuming an electron transfer from $\mathrm{Ca}$ towards $\mathrm{Al}$, the latter would behave as pseudo-phosphorus and although there is no phase of phosphorus with 
this structure, the $\mathrm{Al}$ array in brownmillerite is similar to the $\mathrm{Sb}$ array in the second phase of $\mathrm{Sb}_{2} \mathrm{O}_{5}$ (Jansen, 1979b; see $\S 2.1$, in which the $\mathrm{Sb}$ atoms also form distorted cubes similar to those of the high-pressure phase of antimony and also to those of bismuth. It should also be pointed out that a difference exists between the $\mathrm{Al}_{2} \mathrm{O}_{5}^{4-}$ skeleton and the $\mathrm{Sb}_{2} \mathrm{O}_{5}$ structure. In the former octahedra and tetrahedra coexist, whereas in the latter all the Sb atoms are octahedrally coordinated, although stoichiometry requires that these octahedra share corners in some directions and edges in others. However, both skeleta are similar (see Fig. 17). It should be added that the $\mathrm{Al}_{2} \mathrm{O}_{5}^{4-}$ skeleton of the brownmillerite structure also shows strong similarities with the structure of the $\alpha$ form of $\mathrm{Sb}_{2} \mathrm{O}_{4}$ (Thornton, 1977). Thus, the structure of the $\mathrm{Al}_{2} \mathrm{O}_{5}^{4-}$ net could be formed by notionally inserting one additional $\mathrm{O}$ atom into the tetrahedral layers of $\mathrm{SbO}_{2}$, breaking the edge-sharing connection and leading to a cornerconnected framework. However, the $\mathrm{Sb}$ subarray in both $\mathrm{Sb}_{2} \mathrm{O}_{5}$ and $\mathrm{SbO}_{2}$ is quite similar and, at the same time, similar to the $\mathrm{Al}$ subarray in $\mathrm{Ca}_{2} \mathrm{Al}_{2} \mathrm{O}_{5}$.

$\mathrm{Ca}_{4} \mathrm{Al}_{6} \mathrm{O}_{13}$ is cubic. The $\mathrm{Al}$ subarray forms a four-connected net similar to that of sodalite. In agreement with the ZintlKlemm concept, three Ca atoms would donate $6 \mathrm{e}^{-}$to the six Al atoms converting them into pseudo-silicon atoms, so justifying the four-connected net. In this compound there is a fourth $\mathrm{Ca}$ atom which does not transfer charge to the $\mathrm{Al}$ atoms. It transfers the two valence electrons to an $\mathrm{O}$ atom which is not bonded to aluminium, but only to the $\mathrm{Ca}$ atoms. The compound should then be formulated as $\mathrm{Ca}_{3}\left(\mathrm{Al}_{6} \mathrm{O}_{12}\right) \cdot \mathrm{CaO}$.

$\mathrm{Ca}_{5} \mathrm{Al}_{6} \mathrm{O}_{14}$ can be interpreted in a similar way. The ten valence electrons of the $\mathrm{Ca}$ atoms are transferred to the $\mathrm{Al}$ atoms. Four $\mathrm{Al}$ atoms each receive two electrons to become pseudo-phosphorus and two $\mathrm{Al}$ atoms each receive one electron to become pseudo-silicon. The Al subarray can be

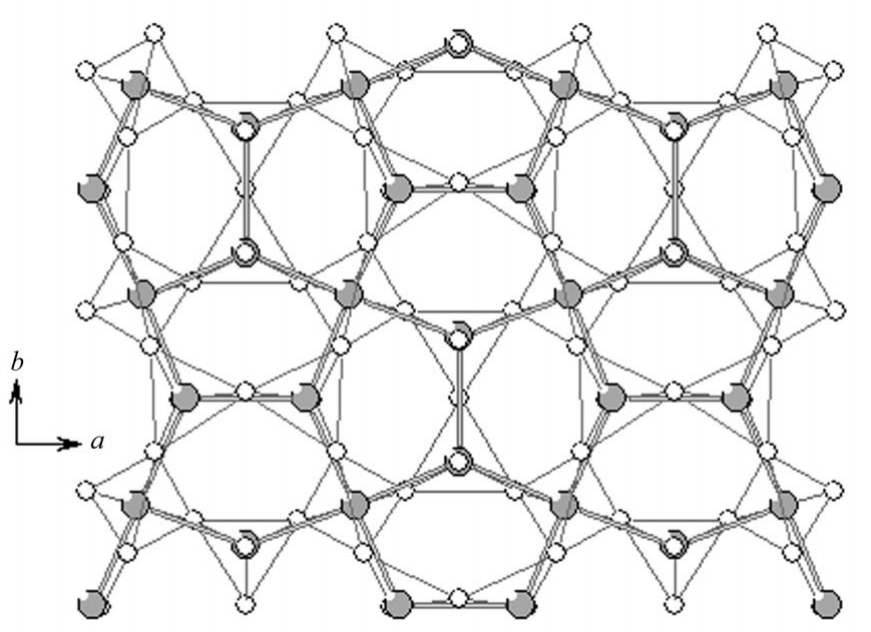

Figure 18

One layer of $\mathrm{AlO}_{4}$ tetrahedra in $\mathrm{Ca}_{5} \mathrm{Al}_{6} \mathrm{O}_{18}$. The $\mathrm{Al}-\mathrm{Al}$ contacts show the existence of four- and three-connected $\mathrm{Al}$ atoms, corresponding to pseudo-silicon and pseudo-phosphorus, respectively. This net is similar to those existing in $\mathrm{GeAs}_{2}$. considered as a pseudo-compound of stoichiometry $\mathrm{P}_{2} \mathrm{Si}$, which consequently has two atoms which are three-connected (P) and one atom which is a four-connected atom ( $\mathrm{Si})$. These atoms form an almost planar McMahon net which is represented in Fig. 18. This net is present in the structure of marcasite $\left(\mathrm{FeS}_{2}\right)$ and surprisingly also exists in $\mathrm{P}_{2} \mathrm{Si}$ itself!

The three compounds $M_{9} \mathrm{Al}_{6} \mathrm{O}_{18}(M=\mathrm{Ca}, \mathrm{Sr}, \mathrm{Ba})$ will be discussed together (Mondal \& Jeffery, 1975; Alonso et al., 1990; Walz et al., 1994; Antipov et al., 1987). The Ca and Sr compounds are isostructural and different from the $\mathrm{Ba}$ compound. In the three compounds the $\mathrm{Al}$ atoms are tetracoordinated. In the $\mathrm{Ca}$ and $\mathrm{Sr}$ compounds the $\mathrm{Al}(\mathrm{O})_{4}$ tetrahedra form isolated six-membered rings which have the chair conformation, such as the $\mathrm{S}_{6}$ molecules (see Fig. 19). However, in the $\mathrm{Ba}$ compounds the $\mathrm{Al}(\mathrm{O})_{4}$ tetrahedra form isolated rings of $12 \mathrm{Al}(\mathrm{O})_{4}$ tetrahedra, in which the $\mathrm{Al}$ atoms adopt the structure of the $S_{12}$ molecule (see Fig. 20). This relationship between the $\mathrm{Al}_{12} \mathrm{O}_{36}$ group and the $\mathrm{S}_{12}$ molecule was pointed out by Walz et al. (1994). These structural coincidences can be
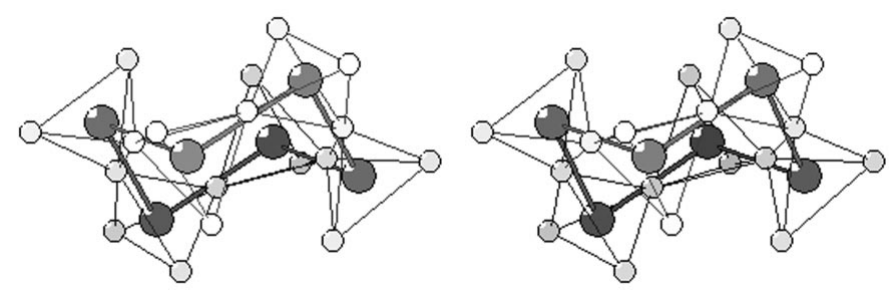

\section{Figure 19}

Stereopair of the six-membered ring $\left(\mathrm{Al}_{6} \mathrm{O}_{18}\right)^{18-}$ in $M_{9} \mathrm{Al}_{6} \mathrm{O}_{18}(M=$ $\mathrm{Ca}, \mathrm{Sr})$. The $\mathrm{Al}$ atoms adopt a chair conformation as in the $\mathrm{S}_{6}$ molecule.

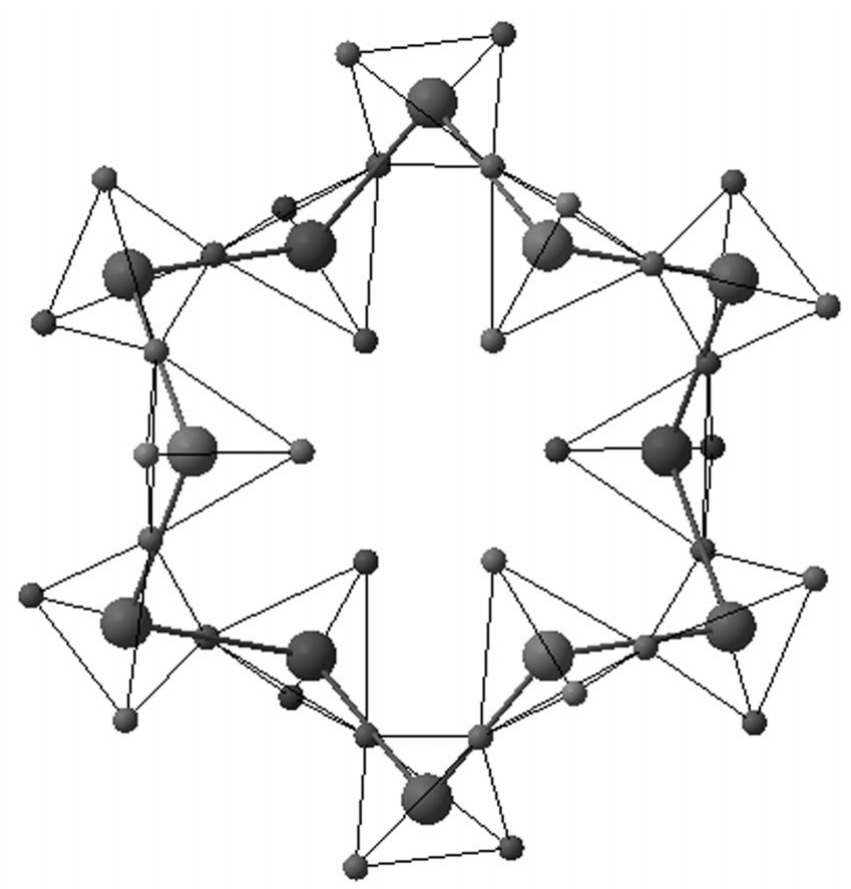

Figure 20

The anionic ring $\left(\mathrm{Al}_{12} \mathrm{O}_{36}\right)^{36-}$ existing in $\mathrm{Ba}_{18} \mathrm{Al}_{12} \mathrm{O}_{36}$. The $\mathrm{Al}$ atoms, bonded by contacts, adopt the structure of the $\mathrm{S}_{12}$ molecules. 
adequately explained following the Zintl-Klemm concept. Thus, the nine alkaline-earth atoms convert the six $\mathrm{Al}$ atoms into pseudo-sulfur and the structures of the existing $\mathrm{S}_{6}$ and $\mathrm{S}_{12}$ molecules are adopted!

The connectivity of the $\mathrm{Al}$ atoms in $\mathrm{Ca}_{12} \mathrm{Al}_{14} \mathrm{O}_{33}$ (Bartl \& Scheller, 1970) can be interpreted in the same way. The $24 \mathrm{Ca}$ atoms contained in the unit cell donate $48 \mathrm{e}^{-}$to the $\mathrm{Al}$ atoms. Of these 16 are converted into pseudo-phosphorus $\left(32 \mathrm{e}^{-}\right)$and 12 are converted into pseudo-silicon. The remaining four electrons are given to two $\mathrm{O}$ atoms which bond uniquely to the $\mathrm{Ca}$ atoms. The $\mathrm{Al}$ atoms then form a rather complicated framework with three- and four-connected atoms, which are in the ratio $4: 3$ as if it was a compound with stoichiometry $\mathrm{P}_{4} \mathrm{Si}_{3}$. Unfortunately, we have not found any analogous compound with this stoichiometry which could present this type of framework.

The structure of $\mathrm{Sr}_{4} \mathrm{Al}_{14} \mathrm{O}_{25}$ is rather complicated. The unit cell contains two formula units and there are six crystallographically independent Al atoms. Three of them, Al4, Al5 and Al6, a total of eight atoms in the unit cell, are octahedrally coordinated, whereas $\mathrm{Al} 1, \mathrm{Al} 2$ and $\mathrm{Al} 3$ are located at the center of the $\mathrm{O}_{4}$ tetrahedra. When these tetrahedral atoms are bonded by contacts (up to $3.46 \AA$ ), it appears as the skeleton depicted in Fig. 21. As seen, there are $12 \mathrm{Al}$ atoms which are five-connected (Al1 and Al3), and eight $\mathrm{Al}$ atoms which are two-connected (A12). To interpret this network we need to again assume the amphoteric character of aluminium and suppose that the octahedrally coordinated $\mathrm{Al}$ atoms donate electrons which are accepted by the $\mathrm{Al}$ atoms which form the tetrahedral framework. Thus, the total number of transferred electrons is 24 from the eight $\mathrm{Al}$ atoms (Al4, Al5 and Al6) plus 16 from the eight $\mathrm{Sr}$ atoms. Of these electrons, eight are transferred to O5, which does not take part in the tetrahedral skeleton but bonds only to the octahedrally coordinated $\mathrm{Al}$ atoms and to strontium. The total amount of $32 \mathrm{e}^{-}$can be donated to the tetrahedral framework. This amount is distributed in the following way: the eight Al2 atoms which show a twofold connectivity are assumed to be pseudo-sulfur,
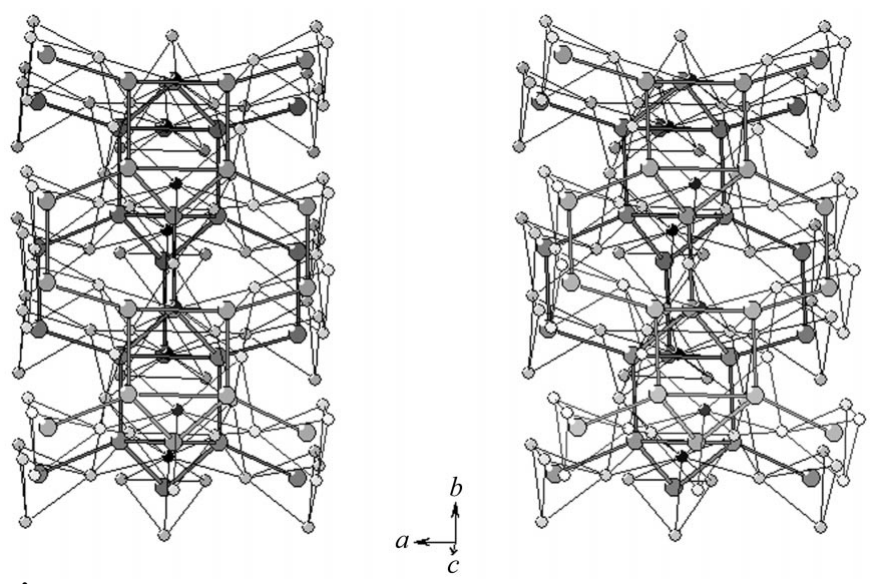

Figure 21

The structure of $\mathrm{Sr}_{4} \mathrm{Al}_{14} \mathrm{O}_{25}$ showing the connectivity of the $\mathrm{Al}$ atoms (five- and two-connected). The $\mathrm{O}$ atoms which lie at the center of $\mathrm{Al}_{3}$ triangles are drawn as small black circles. thus accepting $3 \mathrm{e}^{-}$per atom (24 electrons). The remaining $8 \mathrm{e}^{-}$must be transferred to both Al1 and Al3. As these two atoms are five-connected, the first impression is that they behave as a main-group element, forming $8-N$ bonds. However, to form five two-center, two-electron bonds the $\mathrm{Al}$ atoms would need five electrons and this situation would violate both the octet rule and the $(8-N)$ rule. For this reason, if we assume that each $\mathrm{Al}$ atom retains its three valence electrons it would form only three bonds. The additional electrons needed to form the other two bonds must be provided by the donor cations (octahedral $\mathrm{Al}$ and $\mathrm{Sr}$ ). We have seen that there were eight remaining electrons. If they are transferred to Al1 and Al3 (12 atoms), each would accept $0.666 \mathrm{e}^{-}$. The only way of sharing this fractional charge is to assume the existence of three-center, two-electron bonds. In this way, the octet rule is maintained and the $\mathrm{Al}$ atoms are able to form five bonds. Looking at the oxygen positions we see that there are three $\mathrm{O}$ atoms which are situated midway between the $\mathrm{Al}$ atoms connected by two-center, two-electron bonds and one additional $\mathrm{O}$ atom which is situated just at the center of a $\mathrm{Al}_{3}$ triangle as if it had accepted the two electrons common to the three $\mathrm{Al}$ centers. This $\mathrm{O}$ atom is then common to three $\mathrm{Al}(\mathrm{O})_{4}$ tetrahedra. Two of these three-center, twoelectron bonds should be added to the central Al atom, thus completing the fivefold connectivity.

Finally, $\mathrm{Sr}_{7} \mathrm{Al}_{12} \mathrm{O}_{25}$ (Nevskii et al., 1978), is also a very complicated structure. A projection of the $\mathrm{Al}$ array is represented in Fig. 22. The drawing reveals the existence of very puckered layers of the Kagomé type, which are components of the spinel structure. This seems reasonable because the compound has an $\mathrm{O}$ atom which is not bonded to any $\mathrm{Al}$ atom, in such a way that it could be formulated as $\mathrm{Sr}_{6} \mathrm{Al}_{12} \mathrm{O}_{24} \cdot \mathrm{SrO}$. Thus, it could be seen as an intergrowth of a compound with the spinel stoichiometry $\left(\mathrm{SrAl}_{2} \mathrm{O}_{4}\right)$ and $\mathrm{SrO}$. In fact, when the $\mathrm{Al}$ array is observed from the projection in Fig. 22, one can recognize structural elements of the spinel structure and where all the $\mathrm{Al}$ atoms are four-connected, as if behaving as pseudo-silicon. This is consistent with the transfer of two

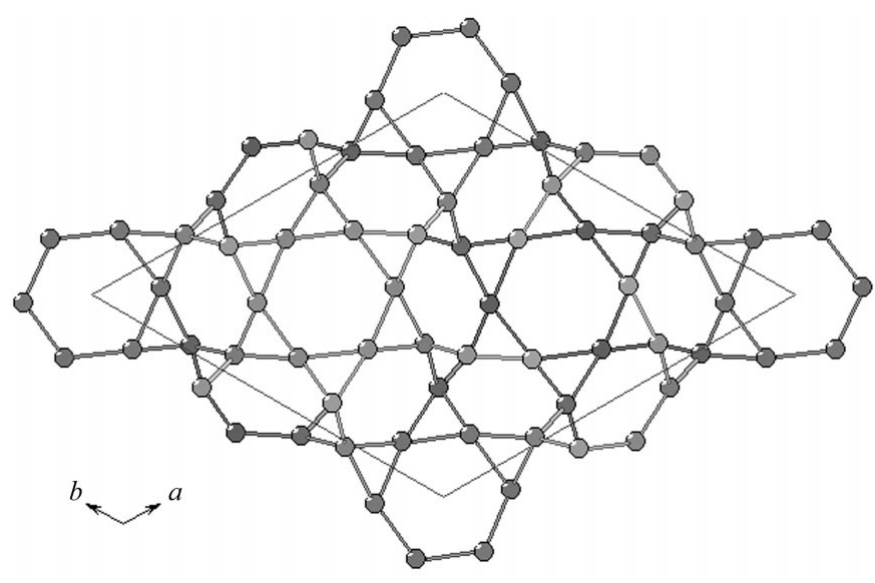

Figure 22

One layer of a four-connected net in $\mathrm{Sr}_{7} \mathrm{Al}_{12} \mathrm{O}_{25}$. This net, formed by the $\mathrm{Al}$ atoms, is a puckered Kagomé net typical of the spinel structure. 
Table 4

Aluminates of the transition metals.

\begin{tabular}{lll}
\hline Compound & Space group & Al skeleton \\
\hline $\mathrm{AgAlO}_{2}$ & $P 6_{3} / m m c$ & $\mathbf{3}^{\mathbf{6}}$ planar nets \\
$\mathrm{AgAl}_{11} \mathrm{O}_{17}$ & $P 6_{3} / m m c$ & $\beta$-Alumina \\
$\mathrm{CuAlO}_{2}$ & $P 6_{3} / m m c$ & $\mathbf{3}^{\mathbf{6}}$ planar nets \\
$\mathrm{Cu}_{2}{ }^{\mathrm{I}} \mathrm{Al}_{4} \mathrm{O}_{7}$ & $F \overline{4} m$ & Variant of spinel \\
$\mathrm{TiAl}_{2} \mathrm{O}_{5}$ & $C m c m$ & Pseudo-P $\left(\mathrm{P}_{2} \mathrm{O}_{5}\right.$ layers $)$ \\
$\mathrm{Ti}_{7} \mathrm{Al}_{2} \mathrm{O}_{15}$ & $C 2 / m$ & Pseudo-S; linear chains of tetrahedra \\
$\mathrm{AlV}_{2} \mathrm{O}_{4}$ & $F d \overline{3} m$ & Direct spinel \\
$\mathrm{TaAlO}_{4}$ & $P 4_{2} / m n m, C 2 / m$ & Al and Ta localized in rutile sites; \\
& & Al and Ta in octahedral holes \\
$\mathrm{FeAl}_{2} \mathrm{O}_{4}$ & $F d \overline{3} m$ & Spinel \\
$\mathrm{FeAlO}_{3}$ & $P n a 2_{1}($ hcp-O) & Chains of pseudo-S $\left(111\right.$ and $\left.116^{\circ}\right)$ \\
$\mathrm{AlWO}_{4}$ & $C 2 / m$ & Fragments of Al metal \\
$\mathrm{Al}_{2}\left(\mathrm{WO}_{4}\right)_{3}$ & $P b c n, P 2_{1}$ & Isolated $\mathrm{Al}(\mathrm{O})_{6}$ octahedra \\
$\mathrm{Al}_{2}\left(\mathrm{WO}_{4}\right)_{3}$ & $P b c n, P 2_{1} / a$ & Isolated $\mathrm{Al}(\mathrm{O})_{6}$ octahedra \\
\hline
\end{tabular}

electrons from strontium to the two $\mathrm{Al}$ atoms, converting them into pseudo-silicon. The other $\mathrm{Sr}$ atom gives charge directly to the free oxygen. It is interesting to see how the spinel structure, which should not be stable because strontium should occupy tetrahedral sites, is not completely lost, producing at the same time, an $\mathrm{AlO}_{2}$ framework which is consistent with the Zintl-Klemm concept.

\subsection{The rare-earth aluminates}

Most of these compounds belong to two great families of structures, i.e. compounds of the general formula (RE) $\mathrm{AlO}_{3}$ and the garnets of the general formula $(\mathrm{RE})_{3} \mathrm{Al}_{5} \mathrm{O}_{12}$. In addition, two compounds with the formula $(\mathrm{RE}){ }_{4} \mathrm{Al}_{2} \mathrm{O}_{9}(\mathrm{RE}=$ $\mathrm{Y}, \mathrm{Eu}$ ) have been reported (Brandle \& Steinfink, 1969).

The (RE) $\mathrm{AlO}_{3}$ compounds exist as two different phases. A high-temperature phase, obtained over $1273 \mathrm{~K}$ with the perovskite structure has been reported for $(\mathrm{RE})=\mathrm{Sc}, \mathrm{Y}, \mathrm{La}$, $\mathrm{Ce}, \mathrm{Pr}, \mathrm{Nd}, \mathrm{Sm}, \mathrm{Tb}, \mathrm{Dy}$ and Ho. Among these there are tetragonal and rhombohedral distortions of the perovskite structure, although the most frequent structure is the orthorhombic distortion (Pnma; Diehl \& Brandt, 1975), isostructural to the $(\mathrm{RE}) \mathrm{FeO}_{3}$ oxides. The second phase reported is hexagonal (space group $P 6_{3} / m m c$; Bertaut \& Mareschal, 1963). It has been synthesized below $1173 \mathrm{~K}$ and could be considered as an intermediate step in the formation of the perovskite structure. The cation array of the perovskite-type phases has been previously studied. The (RE)Al substructure is of the $\mathrm{CsCl}$ type and has the same topology and dimensions as the (RE)Al alloy itself (Ramos-Gallardo \& Vegas, 1997; Vegas \& Jansen, 2002). Although the perovskite structure has been widely studied and it is believed to be well understood, no satisfactory explanation of its skeleton, formed by cornersharing octahedra, exists. We believe that a more rational description of this structure type can be achieved by applying the Zintl-Klemm concept. In (RE) $\mathrm{AlO}_{3}$ the $\mathrm{Al}$ atoms form a simple cubic net. If we assume that the RE atoms can donate three electrons to the $\mathrm{Al}$ atoms, they would become pseudosulfur adopting so the structure becomes that of a Group 16 element. Although there is no phase of sulfur with this s.c. net, it is similar to the rhombohedral structure of the HP phase of Te, which is also the structure of $\beta$-Po. This structure, with the angle $\alpha=77^{\circ}$, is not far from the structure of $\alpha$-Po which is really simple cubic. Moreover, the $\mathrm{AlO}_{3}$ network is exactly the structure of $\mathrm{TeO}_{3}$ (see Fig. 23) discussed above. Other perovskites such as $\mathrm{MSnO}_{3}(M=\mathrm{Ca}, \mathrm{Sr}, \mathrm{Ba})$ can also be considered as real stuffed pseudo- $\mathrm{TeO}_{3}$. The perovskite structure is then formed when the $B$ cations are susceptible to transformation into pseudo-tellurium or a pseudo-element of Group 16.

The second family of rare-earth aluminates belongs to the garnet group, corresponding to the formula $(\mathrm{RE})_{3} \mathrm{Al}_{5} \mathrm{O}_{12}$ $(\mathrm{RE}=\mathrm{Y}, \mathrm{Gd}, \mathrm{Tb}, \mathrm{Ho}, \mathrm{Er}, \mathrm{Yb}$ and Lu; Euler \& Bruce, 1965). These compounds were analyzed on the basis of their RE substructure (Ramos-Gallardo \& Vegas, 1997). In the garnet structure, the RE atoms are eightfold coordinated by $\mathrm{O}$ atoms; two $\mathrm{Al}$ atoms are octahedrally coordinated and three $\mathrm{Al}$ atoms are tetrahedrally coordinated, forming isolated $\mathrm{Al}(\mathrm{O})_{4}$ tetrahedra. The compound could then be formally formulated as $(\mathrm{RE})_{3}^{3+}(\mathrm{Al})_{2}^{3+}\left(\mathrm{AlO}_{4}\right)_{3}^{5-}$, indicating that aluminium also behaves amphoterically here, with the octahedral $\mathrm{Al}$ atoms acting as donors and the tetrahedral $\mathrm{Al}$ atoms as Zintl acceptors. The $15 \mathrm{e}^{-}$donated by the three RE atoms and the two $\mathrm{Al}$ atoms convert the remaining three $\mathrm{Al}$ atoms into a pseudo-noble gas with $8 \mathrm{e}^{-}$in the valence shell, which are later taken by the four $\mathrm{O}$ atoms.

The last compounds in this section are $\mathrm{Eu}_{4} \mathrm{Al}_{2} \mathrm{O}_{9}$ and $\mathrm{Y}_{4} \mathrm{Al}_{2} \mathrm{O}_{9}$. They are isostructural and consist of $(\mathrm{RE})^{3+}$ cations, and $\mathrm{O}^{2-}$ and $\left(\mathrm{Al}_{2} \mathrm{O}_{7}\right)^{8-}$ anions. Here, the transfer of $4 \mathrm{e}^{-}$from the (RE) atoms to the $\mathrm{Al}$ atoms converts them into pseudohalogens, producing the $\mathrm{Al}_{2} \mathrm{O}_{7}$ group with the same structure as the $\mathrm{Cl}_{2} \mathrm{O}_{7}$ molecule. The remaining electrons are transferred directly to two $\mathrm{O}$ atoms which are bonded uniquely to the (RE) atoms and which are located at the center of the $(\mathrm{RE})_{4}$ tetrahedra. The question which arises here is why the charge transfer does not progress up to convert the $\mathrm{Al}$ atoms into a pseudo-noble gas, producing isolated $\left(\mathrm{AlO}_{4}\right)^{5-}$ tetrahedra as in the garnet-type compounds.

\subsection{Aluminates of the transition metals}

The compounds considered in this section are listed in Table 4. In most of these compounds the $\mathrm{Al}$ atoms appear hexacoordinated and inserted into the octahedral holes of closepacked arrays of $\mathrm{O}^{2-}$ anions. This is the case of delafossites $\mathrm{AgAlO}_{2}$ and $\mathrm{CuAlO}_{2}$, the $\beta$-alumina-like structure of $\mathrm{AgAl}_{11} \mathrm{O}_{17}$, the spinel $\mathrm{FeAl}_{2} \mathrm{O}_{4}$ and also $\mathrm{TaAlO}_{4}$, where the Ta and $\mathrm{Al}$ atoms are statistically distributed at the $\mathrm{Ti}$ sites of a rutile-like structure. In $\mathrm{AlWO}_{4}$ the $\mathrm{Al}$ atoms behave as cations, giving electrons to the more electronegative $\mathrm{W}$ atom (Pauling, 1960), which forms isolated $\mathrm{WO}_{4}^{3-}$ anions. As with most of the aluminium-containing oxides where aluminium behaves as a donor, $\mathrm{Al}$ reproduces the $\mathrm{Al}-\mathrm{Al}$ distance of the pure metal $(2.86 \AA)$. In the compounds $\mathrm{Al}_{2}\left(\mathrm{WO}_{4}\right)_{3}$ and $\mathrm{Al}_{2}\left(\mathrm{MoO}_{4}\right)_{3}$ the $\mathrm{Al}$ atoms are so diluted that they form isolated $\mathrm{Al}(\mathrm{O})_{6}$ octahedra.

In the remaining compounds the $\mathrm{Al}$ atoms appear tetracoordinated by four $\mathrm{O}$ atoms. In $\mathrm{Cu}_{2} \mathrm{Al}_{4} \mathrm{O}_{7}$, as in the spinels, the cations are arranged as in the Laves phases (Meyer \& 
Müller-Buschbaum, 1981). However, this structure differs from spinels. The $\mathrm{O}$ atoms are arranged in such a way that they produce tetrahedral coordination around the $\mathrm{Al}$ atoms $\left(M^{\mathrm{VI}}\right.$ atoms in spinels) and an octahedral coordination around the $\mathrm{Cu}^{\mathrm{I}}$ atoms (the tetrahedral $A$ cations in spinels). As a consequence the $\mathrm{Al}$ atoms form the same array as they do in $\mathrm{MgAl}_{2} \mathrm{O}_{4}$, also maintaining the distance of $2.86 \AA$, which is characteristic of the $\mathrm{Al}$ metal and all the compounds where the $\mathrm{Al}$ atoms are octahedrally coordinated. In view of the electronegativity values for $\mathrm{Cu}$ and $\mathrm{Al}$ (1.90 and 1.61, respectively; Pauling, 1960), electron transfer from $\mathrm{Cu}$ to $\mathrm{Al}$ may not necessarily occur and maybe the best way of interpreting this structure is to consider the cations as forming a true alloy, as discussed above for the spinel itself. The same can be said of the true spinel $\mathrm{AlV}_{2} \mathrm{O}_{4}$ (Reuter et al., 1983), in which the $\mathrm{Al}$ atoms occupy the tetrahedral interstices.

$\mathrm{FeAlO}_{3}$ (Bouree et al., 1996) has an h.c.p. (hexagonal closepacked) array of anions. Half of its octahedral holes are occupied by $\mathrm{Fe}$ atoms and half by $\mathrm{Al}$ atoms. The remaining $\mathrm{Al}$ atoms are inserted into $1 / 12$ of the tetrahedral holes. However, this occupancy is not random, but they occupy contiguous tetrahedra forming chains of corner-connected tetrahedra in which the Al atoms also form planar chains with angles of 111 and $116^{\circ}$, similar to those formed by the Si atoms (pseudosulfur) in the Zintl-phase BaSi or those formed by selenium in $\mathrm{Se}_{2} \mathrm{O}_{5}$. This can be interpreted as if the $\mathrm{Fe}$ atoms are not electropositive enough to transfer electrons to the $\mathrm{Al}$ atoms. Instead, the electrons ( 3 per atom) are transferred from the $\mathrm{Al}$ atoms occupying the octahedral holes, converting them into pseudo-sulfur. It is noteworthy that in this structure the $\mathrm{Al}(\mathrm{O})_{4}$ chains are not isolated, as in other structures described in the above sections, but they are inserted in a close-packed array. Nevertheless, the pseudo-sulfur chains are recognisable.

A similar feature is observed in $\mathrm{Ti}_{7} \mathrm{Al}_{2} \mathrm{O}_{15}$ (Remy et al., 1988). Here, the $\mathrm{Al}$ atoms also form chains of cornerconnected tetrahedra. However, in this compound the $\mathrm{Al}$ chains are linear ( $\mathrm{Al}-\mathrm{Al}$ distance of $2.97 \AA$ ) and are embedded in a distorted close-packed array of $\mathrm{O}$ atoms. The Al array could also be considered as pseudo-sulfur (twofold connectivity), but the fact that they do not form an isolated

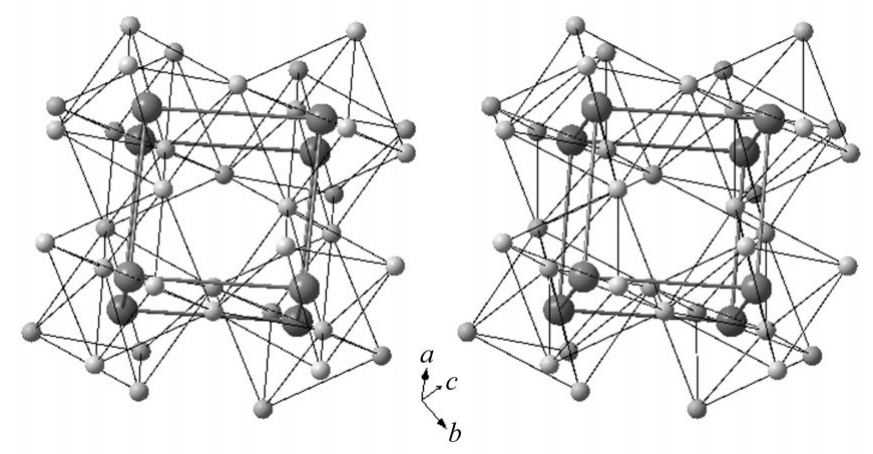

Figure 23

Stereopair of the structure of $\mathrm{TeO}_{3}$ to show its similarity with the perovskite structure. polyanion indicates that the $\mathrm{Ti}$ atoms are not electropositive enough to transform the $\mathrm{Al}$ atoms into a pseudo-atom of the main group. This pattern resembles that observed in $\mathrm{Cu}_{2} \mathrm{Al}_{4} \mathrm{O}_{7}$ discussed above.

The last compound to be discussed is $\mathrm{TiAl}_{2} \mathrm{O}_{5}$ (Moroson \& Lynch, 1972). In this compound the $\mathrm{Ti}$ and $\mathrm{Al}$ atoms are statistically distributed in the same octahedral positions as an irregular close-packed array of $\mathrm{O}$ atoms. The impression is that neither Ti nor $\mathrm{Al}$ is capable of transforming the other into a pseudo-atom. This is in agreement with the electronegativity values of both elements (1.54 and 1.61 for $\mathrm{Ti}$ and $\mathrm{Al}$, respec-

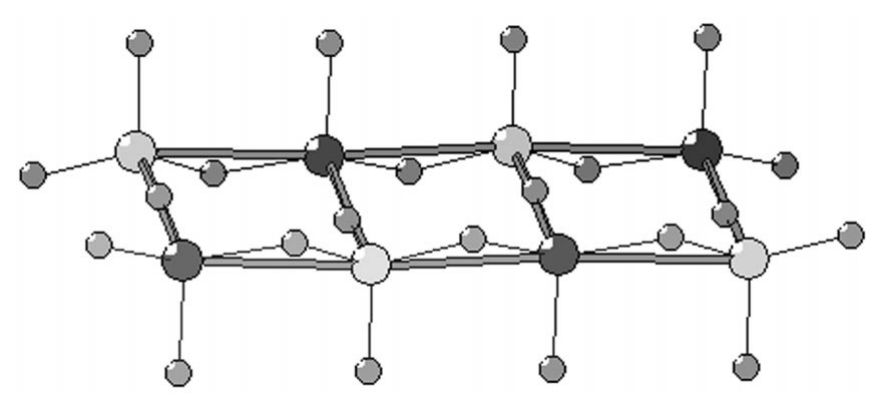

Figure 24

One double chain of three-connected $\mathrm{SiO}_{4}$ and $\mathrm{AlO}_{4}$ tetrahedra, which is present in $\mathrm{Al}_{2} \mathrm{SiO}_{5}$ (sillimanite). Large circles represent $\mathrm{Al}$ (dark grey) and $\mathrm{Si}$ (light grey). Small circles represent $\mathrm{O}$ atoms which lie midway between the $\mathrm{Al}-\mathrm{Si}$ contacts and on the lone pairs. The structure is similar to that of $\mathrm{Sb}_{2} \mathrm{O}_{3}$ represented in Fig. 6. In sillimanite, an additional $\mathrm{O}$ atom is situated on the free lone pairs.

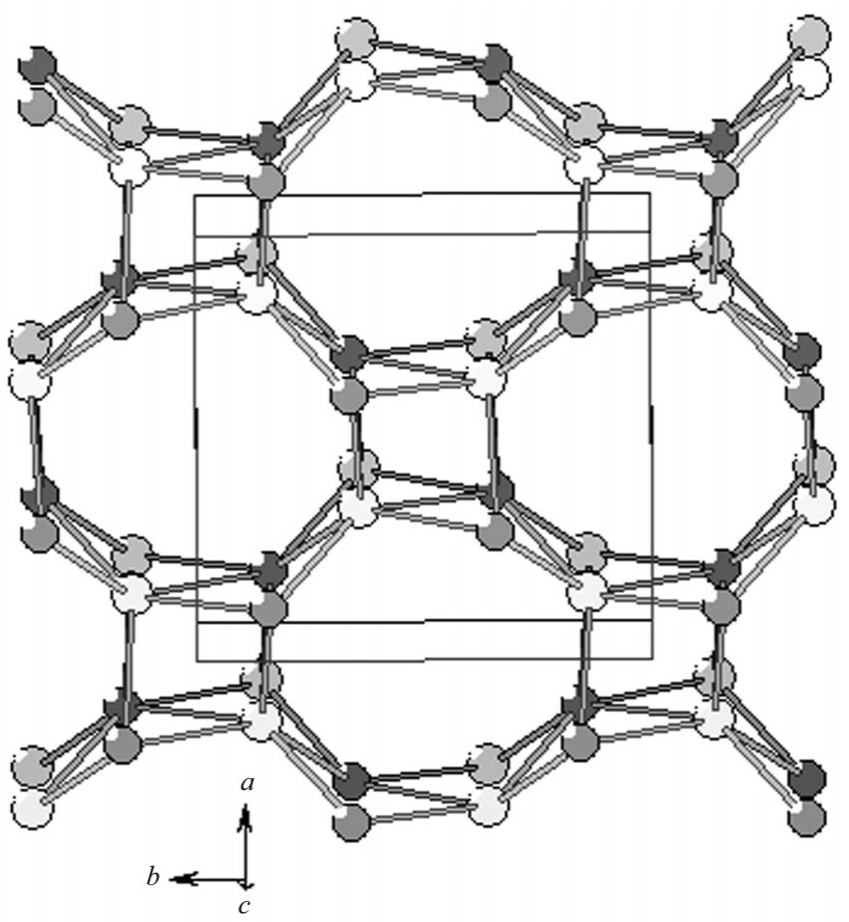

Figure 25

The $\mathrm{Bi}-\mathrm{Al}$ skeleton in $\mathrm{Bi}_{2} \mathrm{Al}_{4} \mathrm{O}_{9}$ which resembles the $\beta$ - $\mathrm{BeO}$ and metavariscite networks (compare with Fig. 9). Dark circles: Al; light circles: Bi. As seen, all atoms are six-connected as in the Zintl phase $\mathrm{K}_{0.4} \mathrm{Cd}_{2}$. 
tively). As discussed above, this is the general trend in the transition metal aluminates.

\subsection{Miscellaneous compounds}

Two thallium aluminates have been reported. One, $\mathrm{Tl}_{2} \mathrm{O}\left(\mathrm{Al}_{2} \mathrm{O}_{3}\right)_{11}$, is a $\beta$-alumina which has already been considered. The other, $\mathrm{TlAlO}_{2}$, is a trigonally distorted stuffed cristobalite in which the more electropositive $\mathrm{Tl}$ atom donates one electron to an $\mathrm{Al}$ atom, converting it into a pseudo-silicon and adopting the diamond structure.

Three lead aluminates are collected. One is also $\beta$-alumina $\left(\mathrm{PbAl}_{12} \mathrm{O}_{19}\right)$, with the $\mathrm{Al}$ atoms coordinated octahedrally by six $\mathrm{O}$ atoms. All the $\mathrm{Al}$ atoms in the other two aluminates are in a tetrahedral coordination and their skeleta can be explained by means of the Zintl-Klemm concept. The structure of $\mathrm{PbAl}_{2} \mathrm{O}_{4}$ (Marsh \& Bernal, 1995) is a stuffed trydimite in which the $\mathrm{Pb}$ atom donates two electrons to the $\mathrm{Al}$ atoms, converting them into pseudo-silicon and adopting the structure of hexagonal diamond (also existing in $\mathrm{Si}$ ). The third compound, $\mathrm{Pb}_{9} \mathrm{Al}_{8} \mathrm{O}_{21}$ (Plötz \& Müller-Buschbaum, 1981), presents a complicated skeleton in which four-connected and three-connected $\mathrm{Al}$ atoms coexist. It can be explained by assuming that the nine $\mathrm{Pb}$ atoms donate $18 \mathrm{e}^{-}$to the $\mathrm{Al}$ atoms. Of these, $12 \mathrm{e}^{-}$are transferred towards six $\mathrm{Al}$ atoms, transforming them into pseudo-phosphorus, and $2 \mathrm{e}^{-}$are given to two $\mathrm{Al}$ atoms, becoming pseudo-silicon. The four remaining electrons are transferred directly towards two $\mathrm{O}$ atoms which do not bond to the $\mathrm{Al}$ atoms, only to $\mathrm{Pb}$ atoms. The reason why the electron transfer is distributed in this way is unknown to us, but this concept can account for this complicated skeleton.

The next compounds to be discussed are the four ternary aluminium silicates. They are the minerals pyrophyllite

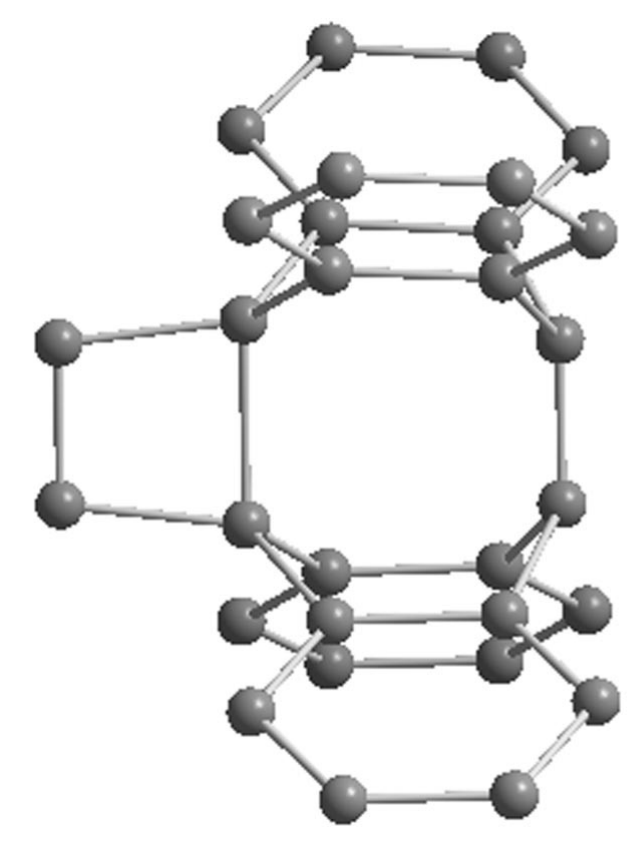

Figure 26

Cycloaddition product of tetradehydroanthracene. This organic molecule contains fragments of the structure of tetragonal carbon as in $\beta$-BeO.
$\left(\mathrm{Al}_{2} \mathrm{Si}_{4} \mathrm{O}_{11}\right.$; Wardle \& Brindley, 1972) and the three phases of $\mathrm{Al}_{2} \mathrm{SiO}_{5}$ (kyanite, sillimanite and andalusite; Burnhan, 1961, $1963 a, b)$. Pyrophylite, $\mathrm{Al}_{2}\left(\mathrm{Si}_{4} \mathrm{O}_{10}\right) \mathrm{O}$, is formed by infinite layers of three-connected $\mathrm{SiO}_{4}$ tetrahedra which build layers formed by hexagonal rings. The $\mathrm{Al}$ atoms are inserted between the layers and are five-coordinated by $\mathrm{O}$ atoms belonging to the two contiguous layers, plus an additional oxygen which does not bond to silicon. The Si-containing layers have then the stoichiometry $\mathrm{Si}_{2} \mathrm{O}_{5}$ and can be compared with one of the phases of $\mathrm{P}_{2} \mathrm{O}_{5}$ discussed earlier. They differ, however, in that $\left[\mathrm{Si}_{2} \mathrm{O}_{5}\right]^{2-}$ is planar, whereas in $\mathrm{P}_{2} \mathrm{O}_{5}$ the layers are puckered as in As itself. However in both compounds, the $\mathrm{Si}-\mathrm{Si}(\mathrm{P}-\mathrm{P})$ connectivity is threefold. Thus, this Si skeleton can be rationalized by assuming that four electrons are transferred from the more electropositive atom ( $\mathrm{Al})$ to the more electronegative atom $\mathrm{Si}$, which is structurally transformed into a pseudo-phosphorus. The two remaining electrons are given directly to the $\mathrm{O}$ atom which bonds only to the $\mathrm{Al}$ atoms. As discussed in other cases, the $\mathrm{O}$ atoms belonging to the $\left(\mathrm{Si}_{2} \mathrm{O}_{5}\right)^{2-}$ layers are located close to the midpoint of the $\mathrm{Si}-\mathrm{Si}$ contacts and near the free-electron pair of each pseudophosphorus atom, thus confirming the tetrahedral coordination.

The three phases of $\mathrm{Al}_{2} \mathrm{SiO}_{5}$ possess completely different structures. In kyanite, there are isolated $\mathrm{SiO}_{4}^{4-}$ groups which can be interpreted as if the Si receives four electrons from the two $\mathrm{Al}$ atoms. The two remaining electrons are transferred to an $\mathrm{O}$ atom which only bonds to the $\mathrm{Al}$ atoms.

In sillimanite, however, the $\mathrm{Al}$ atoms behave amphoterically and one $\mathrm{Al}$ atom (octahedral) transfers its electrons to the other $\mathrm{Al}$ atom $\left(2 \mathrm{e}^{-}\right)$and to the $\mathrm{Si}$ atom $\left(1 \mathrm{e}^{-}\right)$, both becoming pseudo-phosphorus. Consequently, the $\left(\mathrm{Al}_{2} \mathrm{Si}_{2} \mathrm{O}_{5}\right.$ skeleton (represented in Fig. 24) is similar to that of $\mathrm{Sb}_{2} \mathrm{O}_{3}$ (see Fig. 6). However, in the silicate, additional $\mathrm{O}$ atoms are located close to the lone pair region of each $(\mathrm{Si}, \mathrm{Al})$ atom.

The structure of andalusite is more complicated. In this compound the $\mathrm{Al} 2$ atoms are penta-coordinated by $\mathrm{O}$ atoms, whereas the Si atoms are tetrahedrally coordinated. The other $\mathrm{Al}$ atom, Al1, is octahedrally coordinated. One $\mathrm{O}$ atom is bonded only to this $\mathrm{Al}$ atom. All attempts to describe this structure in terms of a framework composed of $\mathrm{Si}$ and $\mathrm{Al} 2$ atoms were unsuccessful. It seems that penta-coordinated aluminium should be considered as a donor atom and not as an acceptor. For this reason it seems more reasonable to consider andalusite, like kyanite, as an orthosilicate in which both $\mathrm{Al}$ atoms donate their electrons to both the $\mathrm{Si}$ atom and the $\mathrm{O}$ atom not bonded to silicon. This agrees with the fact that the $\mathrm{O}$ atoms are not located near the midpoint of the cation-cation contacts, thus making an interpretation similar to that made for other compounds difficult. It should be added that the different structures shown by the three phases of $\mathrm{Al}_{2} \mathrm{SiO}_{5}$ should be correlated with the differences in directions of the electron transfer from the $\mathrm{Al}$ atoms and that these differences must be, in turn, correlated with the synthesis conditions of these minerals. All three are metamorphic minerals, formed under high-pressure and high-temperature conditions, existing in a triple point at $873 \mathrm{~K}$ and $6 \mathrm{Kbar}$, 
where all the three phases coexist (Winkler, 1974). An interesting property of these minerals is that, although the three phases are formed under extreme conditions, kyanite and andalusite phases are converted, by heating, into the sillimanite structure (Winkler, 1974). This feature is consistent with the coordination polyhedra shown by the three phases. Thus, an increase in the coordination number (kyanite and andalusite) should correspond to higher pressures in the formation conditions. Consequently, heating would release this pressure and would give rise to the structure which is stable at lower pressures, which, at the same time, shows a lower coordination number for the $\mathrm{Al}$ atoms (sillimanite).

In $\mathrm{Al}_{2} \mathrm{Ge}_{2} \mathrm{O}_{7}$ (Agafonov et al., 1986), the $\mathrm{Al}$ atoms appear to be penta-coordinated. If we assume that the two $\mathrm{Al}$ atoms donate six electrons to the Ge atoms, they would be converted into a pseudo-halogen molecule whose structure is identical to that of $\mathrm{Cl}_{2} \mathrm{O}_{7}$. One $\mathrm{O}$ atom is located close to the $X-X$ bond and the other six close to the six lone pairs of the two $X$ atoms, thus forming two corner-connected tetrahedra.

$\mathrm{Al}_{3} \mathrm{O}_{3} \mathrm{~N}$ (Yamaguchi \& Yanagida, 1959) is an oxide nitride with the spinel structure in which two $\mathrm{Al}$ atoms are hexacoordinated and one tetra-coordinated. As discussed earlier for the other spinels, the structure could be interpreted by electron transfer from the octahedral $\mathrm{Al}$ atom towards the tetrahedral $\mathrm{Al}$ atom. It is clear that only $5 \mathrm{e}^{-}$are needed to convert the $\mathrm{Al}$ atom into an $\mathrm{AlO}_{4}^{5-}$ anion, but in this case the structure contains an $\mathrm{N}$ atom which is capable of accepting an additional electron.

$\mathrm{Al}\left(\mathrm{PO}_{3}\right)_{3}$ crystallizes in two different phases. The first, $I 4 \overline{3} d$ (Pauling \& Sherman, 1937), contains $\left[\mathrm{P}_{4} \mathrm{O}_{12}\right]^{4-}$ anions of the tetramer in which the $\mathrm{P}$ atoms form puckered four-membered rings. This polyanion can be interpreted as if the $\mathrm{Al}$ atom was donating three electrons to three $\mathrm{P}$ atoms, converting them into pseudo-sulfur and adopting the structure of $\mathrm{S}_{4}$, which also exists for $\mathrm{Se}_{4}$. Although, the $\mathrm{S}_{4}$ molecules have been experimentally observed with two different conformations (Boumedien et al., 1999; Chen et al., 2001), none of them correspond to the conformation observed in the $\mathrm{P}_{4} \mathrm{O}_{12}$ group. However, the possible existence of this puckered fourmembered ring has been postulated for both the $\mathrm{S}_{4}$ and the $\mathrm{Se}_{4}$ molecules, from theoretical calculations (Chen et al., 2001; Brabson \& Andrews, 1992). In the second phase (Van der Meer, 1976), the electron transfer is similar but the $\mathrm{PO}_{3}^{3-}$ groups form infinite chains, as in the structure of asbestos-like $\mathrm{SO}_{3}$. The $\mathrm{P}$ substructures then resemble the structure of fibrous sulfur.

The structures of $\mathrm{AlPO}_{4}$ and $\mathrm{AlAsO}_{4}$ were discussed in $\$ 2.1$. $\mathrm{Bi}_{2} \mathrm{Al}_{4} \mathrm{O}_{9}$ (Niizeki \& Wachi, 1968) is another structure whose interpretation is not straightforward. In this compound the $\mathrm{Bi}$ atoms and half the $\mathrm{Al}$ atoms are tetrahedrally coordinated by $\mathrm{O}$ atoms, whereas the other half of the $\mathrm{Al}$ atoms are located in $\mathrm{O}_{6}$ octahedra. The cation array of this compound is represented in Fig. 25 and also shows strong similarities with that of $\beta$ - $\mathrm{BeO}$ and metavariscite (see Fig. 9). In $\mathrm{Bi}_{2} \mathrm{Al}_{4} \mathrm{O}_{9}$, the $\mathrm{Bi}$ atoms and the tetrahedral $\mathrm{Al}$ atoms form $\mathbf{4 . 8}^{2}$ layers, whereas the octahedral $\mathrm{Al}$ atoms are inserted into the octagonal tunnels formed in the $\mathrm{Bi}-\mathrm{Al}$ framework. In spite of the similarities with $\beta$ - $\mathrm{BeO}$, both structures differ in how the $\mathbf{4 . 8 ^ { 2 }}$ layers are connected in the direction perpendicular to the projection plane. Thus, in $\beta$ - $\mathrm{BeO}$, the connectivity is four, whereas in $\mathrm{Bi}_{2} \mathrm{Al}_{4} \mathrm{O}_{9}$ the $\mathbf{4 . 8 ^ { 2 }}$ layers are stacked in such a way that each $\mathrm{Bi}(\mathrm{Al})$ atom is connected to six unlike atoms, forming a network similar to that found in the Zintl phase $\mathrm{K}_{0.4} \mathrm{Cd}_{2}$ (Todorov \& Sevov, 1998). Another feature is that the tetrahedral $\mathrm{Al}$ atoms form dumbbells, separated by a distance of $3.45 \AA$. Since these two $\mathrm{Al}$ atoms are tetrahedrally coordinated, the result is the formation of $\mathrm{Al}_{2} \mathrm{O}_{7}$ groups composed of two corner-connected tetrahedra. The formation of these groups could be interpreted as if each Al2 atom and the Bi atoms were to donate three electrons. Two of these electrons are accepted by the $\mathrm{O}$ atoms which bond to both $\mathrm{Al} 2$ and bismuth, and the remaining four are transferred to the Al1 atoms which behave as pseudo-halogens, thus forming an anion with the same structure as $\mathrm{Cl}_{2} \mathrm{O}_{7}$. In the $\mathrm{Al}_{2} \mathrm{O}_{7}$ group, the central $\mathrm{O}$ atom is located in the centre of the $\mathrm{A}-\mathrm{Al}$ contact, thus producing a longer distance than in other tetrahedral aluminate groups $(\simeq 3.10-3.20 \AA)$.

The only known ternary aluminium oxide with the group 16 elements is $\mathrm{Al}_{2}\left(\mathrm{SO}_{4}\right)_{3}($ Dahmen \& Gruehn, 1993). Here the $\mathrm{Al}$ atoms are octahedrally coordinated and donate their six electrons to the $\mathrm{S}$ atoms which become a pseudo-noble gas, thus forming the isolated $\mathrm{SO}_{4}^{2-}$ anions. Its structure is of the corundum type, virtually equal to that of the sulfide $\mathrm{Al}_{2} \mathrm{~S}_{3}$ (Flahaut, 1952). $\mathrm{Al}_{2}\left(\mathrm{SO}_{4}\right)_{3}$ and $\mathrm{Al}_{2} \mathrm{O}_{3}$ provide a new example of structural identity between the cation array in the oxide and the corresponding alloy, as has been reported for many other oxides and alloys (Vegas \& Jansen, 2002).

We will end this section with the description of aluminium borates. Of these, the HP phase $\mathrm{AlBO}_{3}$ (Vegas et al., 1977) presents the calcite-type structure. The $\mathrm{Al}$ atoms are hexa coordinated and donate their electrons to the $\mathrm{BO}_{3}^{3-}$ group. $\left(\mathrm{Al}_{2} \mathrm{O}_{3}\right)_{10}\left(\mathrm{~B}_{2} \mathrm{O}_{3}\right)_{2}$ is mainly aluminium oxide and will not be discussed here. $\mathrm{Al}_{4} \mathrm{~B}_{2} \mathrm{O}_{9}$ presents disorder and will not be commented. The last compound to be considered is $\mathrm{Al}_{5}\left(\mathrm{BO}_{3}\right) \mathrm{O}_{6}$ (Sokolova et al., 1978). There are four independent $\mathrm{Al}$ atoms in the asymetric unit. All occupies a site with multiplicity 8 , and Al2, Al3 and Al4 occupy sites with multiplicity 4. Al1 is hexa-coordinated and Al4 is clearly tetrahedrally coordinated. The remaining $\mathrm{Al}$ atoms, $\mathrm{Al} 2$ and $\mathrm{Al} 3$, are also tetra-coordinated up to a distance of $1.85 \AA$. However, both atoms have a fifth $\mathrm{O}$ neighbour at 2.16 and $2.25 \AA$ respectively. On the other hand, the $\mathrm{Al}-\mathrm{Al}$ contacts show a wide variety of distances. Some of them have values around $2.80 \AA$. A second set of distances is around $3.14 \AA$ and finally a third set contains distances of $3.46 \AA$. When contacts are drawn up to $3.14 \AA$, they appear as a pattern with four-, three- and one-connected $\mathrm{Al}$ atoms. However, in this framework the $\mathrm{O}$ atoms do not always appear located near the center of the $\mathrm{Al}-\mathrm{Al}$ contacts and the model applied to the other structures fails. The only way of interpreting the structure is to assume that the Al1, Al2 and $\mathrm{Al} 3$ atoms act as electron donors which are accepted by the Al4 atoms $\left(5 \mathrm{e}^{-}\right)$, forming isolated $\left(\mathrm{AlO}_{4}\right)^{5-}$ anions, the $\mathrm{BO}_{3}$ groups $\left(3 \mathrm{e}^{-}\right)$and the two $\mathrm{O}$ atoms $\left(4 \mathrm{e}^{-}\right)$which only bond to the three donor $\mathrm{Al}$ 
atoms. In this way this compound should be reformulated as $\mathrm{Al}_{4}\left(\mathrm{BO}_{3}\right)\left(\mathrm{AlO}_{4}\right) \mathrm{O}_{2}$. As occurs with other structures where the $\mathrm{Al}$ atoms act as donors the $\mathrm{Al}$ subarray, up to a distance of $2.90 \AA$, consists of fragments of a f.c.c. net reproducing the distances of the $\mathrm{Al}$ metal.

\section{Concluding remarks}

The structures described and the above discussion clearly indicate that the Zintl-Klemm concept is maintained in the oxides and that the atoms forming the Zintl phases, all cations in the oxides, behave structurally as real Zintl phases in spite of being plunged in an oxygen matrix. All these compounds are new examples of how cations, in oxides, recognize themselves as previously stated for many other compounds (Vegas \& Jansen, 2002).

The application of the Zintl-Klemm concept has served to rationalize and understand the structures of 94 aluminates whose skeleta had not been explained as yet and where the $\mathrm{Al}$ atoms occupying tetrahedral holes can be considered as 'cations ex-officio', following the name proposed by Parthé \& Chabot (1990). Now we know that aluminium does not occupy either tetrahedral or octahedral holes as a function of the size of the $\mathrm{Al}^{3+}$ cation (the size should always be the same), but as a function of both the nature of the cations accompanying it in the oxide and of the behaviour of the $\mathrm{Al}$ itself. Thus, very electropositive atoms convert the $\mathrm{Al}$ atoms into a pseudomain group element, thus adopting a tetrahedral coordination, as they do with the majority of binary main-group oxides. On the other hand, when more electronegative atoms, such as $\mathrm{Si}$ or $\mathrm{W}$, coexist with aluminium it donates its valence electrons (behaves as a cation) and adopts an octahedral coordination. Examples of this behaviour are the aluminium silicates and tungstates described above. It should be remembered that this amphoteric character of aluminium was already made clear in the distribution of the $\mathrm{Al}-\mathrm{Al}$ distances in their oxides (Isea et al., 1998). Thus, a structure cannot be completely understood if only the size of the ions is taken into account, as predicted by the ionic model. We also need to know the nature (electronegativity) of all the cations forming the structure.

Good examples of this influence are the compounds $\mathrm{AgAlO}_{2}$ and $\mathrm{LiAlO}_{2}$. Both are aluminates of monovalent cations $\left(\mathrm{Ag}^{+}\right.$and $\left.\mathrm{Li}^{+}\right)$. Both have similar ionic radii ( 0.67 and $0.59 \AA$, respectively). However, $\mathrm{Li}^{+}$forces the $\mathrm{Al}$ atoms to be converted into a pseudo-silicon, whereas $\mathrm{Ag}^{+}$produces a delafossite structure in which the $\mathrm{Ag}^{+}$cations develop their own bonding features, giving rise to $\mathbf{3}^{\mathbf{6}}$ planar nets of both $\mathrm{Ag}$ and $\mathrm{Al}$ atoms. Another interesting example is provided by the oxides $\mathrm{TiAl}_{2} \mathrm{O}_{5}$ and $\mathrm{Ca}_{2} \mathrm{Al}_{2} \mathrm{O}_{5}$. In the former, the Ti atoms are not electropositive enough to convert the $\mathrm{Al}$ atoms into pseudo-phosphorus, both occupying octahedra holes of a closest-packed array of $\mathrm{O}$ atoms, whereas in the latter the $\mathrm{Al}$ atoms adopt the structure of the $\mathrm{Sb}$ atoms in $\mathrm{Sb}_{2} \mathrm{O}_{5}$.

Among the structures discussed we have found many similarities with that of $\beta$-BeO. We have seen that this structure does not exist among the elements of Group 14. It has only been found in a II-VI compound and in the Zintl compound $\mathrm{CrB}_{4}$. Here the question arises as to whether this skeleton might be plausible for either carbon or silicon. In a theoretical study, Burdett \& Canadell (1988) have concluded that this skeleton, also called tetragonal carbon, would be stable only for a v.e.c. (valence electron concentration) either greater or less than four. However, we wish to remember that this network has been obtained in the form of, to date, small molecules such as the cycloaddition products of tetradehydrodianthracene (Battersby et al., 1995; Kammermeier et al., 1997), which are represented in Fig. 26.

Another interesting aspect to be discussed is the positions of the $\mathrm{O}$ atoms in these oxides. As seen along the discussion, all the main-group elements and consequently all the pseudoskeleta formed by the $\mathrm{Al}$ atoms in the oxides produce structures which can be interpreted by the formation of two-center, two-electron bonds, obeying the $8-N$ rule. We have also seen that all the $\mathrm{O}$ atoms are located close to either the bonding pairs or the lone pairs. In this way, in the case of the binary oxides of the main-group elements, the oxides reproduce in most cases, the structure of their respective elements. Since one $\mathrm{O}$ atom is always inserted into a bonding pair, all the elemental structures appear expanded, in the oxides, with respect to the geometries shown by the elements. We can mention the pairs $\mathrm{Si}-\mathrm{SiO}_{2}, \mathrm{P}_{4}-\mathrm{P}_{4} \mathrm{O}_{x}, \mathrm{~S}-\mathrm{SO}_{3}, \mathrm{Te}-\mathrm{TeO}_{3}$ etc. All these oxides are new examples of how the structure of elements (or alloys) are maintained in their oxides and should be added to the more than one hundred examples reported by Vegas \& Jansen (2002).

The location of the $\mathrm{O}$ atoms is related to a very old question concerning the distribution of the valence electrons in metals and alloys. It is commonly accepted that in these structures the valence electrons are delocalized. However, Nesper (1991), referring to an idea of von Schnering, has suggested considering metals and hence alloys as electrides, with free electrons located in the holes of the three-dimensional array of cations. Consequently, the possibility that anions would be located where the free electrons of the metal (alloy) were has been speculated over and the analysis of the positions of the anions could be used to infer the sites of the free electrons in the intermetallic compounds. It is clear that experimental evidence of this hypothesis is difficult to obtain in the case of alloys. However, the compounds we are dealing with here are in agreement with this hypothesis. The tetrahedral coordination shown by most of these structures should not be considered as a size effect, but rather as a consequence of the number of bond and lone pairs which is always four. In connection with this, it should be added that the structures of both $\mathrm{Te}$ and $\mathrm{TeO}_{3}$ admit a similar interpretation. If we consider that the six valence electrons of Te are distributed octahedrally, then each Te atom is able to form two-center, two-electron bonds with its six like neighbours. The $\mathrm{O}$ atoms in $\mathrm{TeO}_{3}$ would be located close to these bonding pairs, thus producing an octahedral coordination. An interesting question related to this problem is why $\mathrm{O}$ atoms see in the same way both the more delocalized bonding pairs and the more localized lone pairs. A nice answer to this question would be that the bonding pairs are also forming non-nuclear maxima 
(NNM) between the two cations (bonded atoms). Regarding the possible existence of these NNM the reader is referred to the article of Martín-Pendás et al. (1999). However, what can be concluded is that an $\mathrm{O}^{2-}$ anion seems to play the same role as a bonding electron pair.

The fact that the $\mathrm{O}$ atoms are normally situated close to (but not exactly at) the middle point of a $X-X$ contact produces the same effect as the rotation of the tetrahedra. This rotation was postulated by O'Keeffe \& Hyde (1981) to derive the real structure of $\beta$-cristobalite (I4-2d) from the nonexisting ideal C9 structure. It can be concluded that the tetrahedra are physically not tilted, only the $\mathrm{O}$ atoms are located 0.5-0.6 $\mathrm{A}$ off the center of the elongated $X-X$ bonds, thus producing $\mathrm{Si}-\mathrm{O}-\mathrm{Si}$ angles of around $140^{\circ}$. In fact, the $\mathrm{Si}$ array is the same and with same dimensions in both the tetragonal and the ideal $\mathrm{C} 9$ structures. When the structure is seen as derived from Si itself, it is unnecessary to postulate the existence of repulsive forces as responsible for the opening of the $\mathrm{Si}-\mathrm{O}-\mathrm{Si}$ angles, as concluded by O'Keeffe \& Hyde (1981).

We have seen that some structures, such as $\mathrm{CaAl}_{4} \mathrm{O}_{7}$ and $\mathrm{Sr}_{4} \mathrm{Al}_{14} \mathrm{O}_{25}$, are difficult to interpret with this model. These difficulties seem to be correlated with the low number of donor cations, thus avoiding the structural transformation of aluminium in pseudo-atoms of higher atomic number. However, it is true that most of the compounds considered here are better understood in the light of these old concepts.

We will finish by saying that this model can also be applied to other families of compounds such as gallates, borates, silicates and phosphates. Similar studies are being carried out for these compounds and will be the object of forthcoming papers.

Work was supported by DGI of MCyT (Spain) under project number BQU2001-1695.

\section{References}

Addison, W. E. (1965). Structural Principles in Inorganic Compounds. London: Longmans.

Agafonov, V., Kahn, A., Michel, D. \& Pérez-Jorba, M. (1986). J. Solid State Chem. 62, 402-404.

Alonso, J. A., Rasines, I. \& Soubeyroux, J. L. (1990). Inorg. Chem. 29, 4768-4771.

Antipov, E. V., Lykova, L. N., Paramova, M. V., Rozanova, O. N. \& Kovba, L. M. (1987). Koord. Khim. 13, 1119-1122.

Arbib, E. H., Elouadi, B., Chaminade, J. P. \& Darriet, J. (1996). J. Solid State Chem. 127, 350-353.

Axel, H., Schaefer, H. \& Weiss, A. (1990). Z. Kristallogr. 193, $217-$ 242.

Barnett, J. D., Bean, V. E. \& Hall, H. T. (1986). High Temp. High Press. 18, 79-85.

Bartl, H. \& Scheller, T. (1970). Neues Jahrb. Mineral. Monatsh. pp. 547-552.

Battersby, T. R., Gantzel, P., Baldridge, K. K. \& Siegel, J. S. (1995). Tetrahedron Lett. 36, 845-848.

Beagley, B., Cruickshank, D. W. J., Hewitt, T. G. \& Haaland, A. (1967). Trans. Faraday Soc. 63, 836-845.

Beagley, B., Cruickshank, D. W. J., Hewitt, T. G. \& Jost, K. H. (1969). Trans. Faraday Soc. 65, 1219-1230.

Bertaut, F. \& Mareschal, J. (1963). C. R. Acad. Sci. Paris, 257, 867870.
Boumedien, M. S., Corset, J. \& Picquenard, E. (1999). J. Raman Spectrosc. 30, 463-472.

Bouree, F., Baudour, J. L., Elbadraoui, E., Musso, J., Laurent, C. \& Rousset, A. (1996). Acta Cryst. B52, 217-222.

Boyko, Z. R. \& Wisnyl, L. G. (1958). Acta Cryst. 11, 444-445.

Brabson, G. D. \& Andrews, L. (1992). J. Phys. Chem. 96, 9172-9177.

Brandle, C. D. \& Steinfink, H. (1969). Inorg. Chem. 8, 1320-1324.

Burdett, J. K. \& Canadell, E. (1988). Inorg. Chem. 27, 4437-4444.

Burnhan, C. W. (1961). Z. Kristallogr. 115, 269-290.

Burnhan, C. W. (1963a). Z. Kristallogr. 118, 337-360.

Burnhan, C. W. (1963b). Z. Kristallogr. 118, 127-148.

Chen, M. D., Liu, M. L., Luo, H. B., Zhang, Q. E. \& Au, C. T. (2001). J. Mol. Struct. (Theochem.) 548, 133-141.

Coppens, P., Yang, Y. W., Blessing, R. H., Cooper, W. F. \& Larsen, F. K. (1977). J. Am. Chem. Soc. 99, 760-766.

Crain, J., Piltz, R. O., Ackland, G. J., Clarck, S. J., Paine, M. C., Milman, V., Lin, J. S., Hatton, P. D. \& Nam, Y. H. (1994). Phys. Rev. $B, \mathbf{5 0}, 8389-8401$.

Cruickshank, D. W. J. (1964). Acta Cryst. 17, 677-679.

Crystal Impact (1998). DIAMOND. Visual Crystal Structure Information System. Crystal Impact, Postfach 1251, D-53002 Bonn, Germany.

Dahmen, T. \& Gruehn, R. (1993). Z. Kristallogr. 204, 57-65.

Dehlinger, U. (1927). Z. Kristallogr. 66, 108-119.

Diehl, R. \& Brandt, G. (1975). Mater. Res. Bull. 10, 85-90.

Eisenmann, B. \& Cordier, G. (1996). Chemistry, Structure and Bonding of Zintl Phases and Ions, edited by S. M. Kauzlarich, ch. 2. Weinheim: VCH.

Euler, F. \& Bruce, J. A. (1965). Acta Cryst. 19, 971-978.

Evers, J. (1978). J. Solid State Chem. 24, 199-207.

Evers, J., Oehlinger, G. \& Weiss, A. (1980). Z. Naturforsch. Teil B, 35, 397-398.

Evers, J., Oehlinger, G. \& Weiss, A. (1983). Z. Naturforsch. Teil B, 38, 899-900.

Flahaut, J. (1952). Ann. Chim. Paris, 7, 632-696.

Frueh, A. J. (1951). Am. Mineral. 36, 316.

Harwig, H. A. (1978). Z. Anorg. Allg. Chem. 444, 151-166.

Hoffmann, R. (1988). Solids and Surfaces. A Chemist's View of Bonding in Extended Structures. Weinheim: VCH.

Husheer, S. L. G., Thompson, J. G. \& Melnitchenko, A. (1999). J. Solid State Chem. 147, 1046.

Iota, V., Yoo, C. S. \& Cynn, H. (1999). Science, 283, 1510-1513.

Isea, R., Vegas, A. \& Ramos-Gallardo, A. (1998). Acta Cryst. B54, 35 40.

Ito, T. \& Sawada, H. (1939). Z. Kristallogr. 102, 13-25.

Ito, S., Suzuki, K., Inagaki, M. \& Naka, S. (1980). Mater. Res. Bull. 15, 925-932.

Jansen, M. (1978). Z. Anorg. Allg. Chem. 441, 5-12.

Jansen, M. (1979a). Z. Naturforsch. Teil B, 34, 10-13.

Jansen, M. (1979b). Acta Cryst. B35, 539-542.

Jansen, M. \& Strojek, S. (1997). Z. Naturforsch. Teil B, 52, 906-910. Jansen, M., Voss, M. \& Deiseroth, H. J. (1981). Angew. Chem. pp. 1023-1024.

Jennings, H. M. \& Richman, M. H. (1976). Science, 193, 1242-1243.

Jost, K. H. (1964). Acta Cryst. 17, 1593-1598.

Jost, K. H. \& Schneider, M. (1981). Acta Cryst. B37, 222-224.

Jung, H. (1926). Centralblatt Miner. Geol. p. 107.

Kaduk, J. A. \& Pei, S.-Y. (1995). J. Solid State Chem. 115, 126-139.

Kahlenberg, V., Fischer, R. X. \& Shaw, C. S. J. (2000). Am. Mineral. 85, 1061-1065.

Kammermeier, S., Jones, P. G. \& Herges, R. (1997). Angew. Chem. Int. Ed. Engl. 36, 1757-1760.

Kelly, B. \& Woodward, P. (1976). J. Chem. Soc. Dalton Trans. pp. 1314-1316.

Klemm, W. (1958). Proc. Chem. Soc. London, pp. 329-341.

Kniep, R. (1978). Habilitationschrift. Universität Düsseldorf, Germany.

Kniep, R. \& Mootz, D. (1973). Acta Cryst. B29, 2292-2294. 
Kniep, R., Mootz, D. \& Vegas, A. (1977). Acta Cryst. B33, 263-265. Kumada, M., Kinomura, M., Woodward, P. M. \& Sleight, A. W. (1995). J. Solid State Chem. 116, 281-285.

Langlet, G. (1964). C. R. Acad. Sci. Paris, 259, 3769-3770.

Leciejewicz, J. (1961). Z. Kristallogr. 116, 345-353.

Lihl, F. (1932). Z. Kristallogr. 81, 142-147.

Lindqvist, O. \& Moret, J. (1973). Acta Cryst. B29, 643-650.

Lueer, B. \& Jansen, M. (1991). Z. Kristallogr. 197, 247-248.

Machida, K. I., Adachi, G. Y. \& Shiokawa, J. (1982). Acta Cryst. B38, 889-891.

Marezio, M. (1965). Acta Cryst. 19, 396-400.

Marezio, M. \& Remeika, J. P. (1966). J. Chem. Phys. 44, 3143-3145.

Marsh, R. E. \& Bernal, I. (1995). Acta Cryst. B51, 300-307.

Martín-Pendás, A., Costales, A., Mori-Sánchez, P. \& Luaña, V. (1999). Phys. Rev. Lett. 83, 1930-1933.

Mattheiss, L. F. (1992). Phys. Rev. B, 45, 3252-3259.

Meyer, H. \& Müller-Buschbaum, H.-K. (1981). Monatsh. Chem. 112, $51-57$.

Miller, G. J. (1996). Chemistry, Structure and Bonding of Zintl Phases and Ions, edited by S. M. Kauzlarich, ch. 1. Weinheim: VCH.

Moebs, M. \& Jansen, M. (1984). Z. Anorg. Allg. Chem. 514, 39-48.

Mondal, P. \& Jeffery, J. W. (1975). Acta Cryst. B31, 689-697.

Morosin, B. \& Lynch, R. W. (1972). Acta Cryst. B28, 1040-1046.

Nesper, R. (1991). Angew. Chem. Int. Ed. Engl. 30, 789-817.

Nevskii, N. N., Glasser, L. D., Ilyukhin, V. V. \& Belov, N. V. (1978). Dokl. Akad. Nauk, 241, 821-824.

Niizeki, N. \& Wachi, M. (1968). Z. Kristallogr. 127, 173-187.

O'Keeffe, M. \& Hyde, B. G. (1981). Structure and Bonding in Crystals, edited by M. O'Keeffe \& A. Nasvrotsky, Vol. I, ch. 10. New York: Wiley.

O'Keeffe, M. \& Hyde, B. G. (1985). Structure and Bonding, Vol. 61, pp. 77-144. Berlin: Springer Verlag.

Parthé, E. \& Chabot, B. (1990). Acta Cryst. B46, 7-23.

Parthé, E. \& Engel, N. (1986). Acta Cryst. B42, 538-544.

Pauling, L. (1960). The Nature of the Chemical Bond. Ithaca: Cornell University Press.

Pauling, L. \& Sherman, J. (1937). Z. Kristallogr. 96, 481-487.

Pearson, W. B. (1964). Acta Cryst. 17, 1-15.

Pilati, T., Demartin, F., Cariati, F., Bruni, S. \& Gramaccioli, C. M. (1993). Acta Cryst. B49, 216-222.

Plötz, K. B. \& Müller-Buschbaum, H.-K. (1981). Z. Anorg. Allg. Chem. 480, 149-152.

Ramos-Gallardo, A. \& Vegas, A. (1995). Z. Kristallogr. 210, 1-2.

Ramos-Gallardo, A. \& Vegas, A. (1996). Z. Kristallogr. 211, 299-303.
Ramos-Gallardo, A. \& Vegas, A. (1997). J. Solid State Chem. 128, 69 72.

Reid, A. F. \& Ringwood, A. E. (1968). Inorg. Chem. 7, 443-445.

Remy, F., Monnereau, O., Casalot, A., Dahan, F. \& Galy, J. (1988). J. Solid State Chem. 76, 167-177.

Reuter, B., Aust, R., Colsmann, G. \& Neuwald, Ch. (1983). Z. Anorg. Allg. Chem. 500, 188-198.

Rohr, C. \& George, R. (1995). Angew. Chem. 34, 2115-2116.

Schnering, H. G. von, Wittmann, M. \& Sommer, D. (1984). Z. Anorg. Allg. Chem. 510, 61-71.

Sclar, C. B., Carrison, L. C., Gager, W. B. \& Stewart, O. M. (1966). J. Phys. Chem. Solids, 27, 1339-1343.

Shannon, R. D. \& Prewitt, C. T. (1969). Acta Cryst. B25, 925-946.

Sokolova, E. V., Azizov, A. V., Simonov, N. A., Leonjuk, N. I. \& Belov, N. V. (1978). Dokl. Akad. Nauk SSSR, 243, 655-658.

Spencer, J. R., Jessup, K. L., McGrath, M. A., Ballester, G. E. \& Yelle, R. (2000). Science, 288, 1208-1210.

Stahl, K., Legros, J. P \& Galy, J. (1992). Z. Kristallogr. 202, 99-107.

Svensson, C. (1974). Acta Cryst. B30, 458-461.

Svensson, C. (1975). Acta Cryst. B31, 2016-2018.

Thornton, G. (1977). Acta Cryst. B33, 1271-1273.

Todorov, E. \& Sevov, S. C. (1998). Inorg. Chem. 37, 6341-6345.

Van der Meer, H. (1976). Acta Cryst. B32, 2423-2426.

Vegas, A. (2000). Crystallogr. Rev. 7, 189-286.

Vegas, A., Cano, F. H. \& García-Blanco, S. (1977). Acta Cryst. B33, 3607-3609.

Vegas, A. \& Jansen, M. (2002). Acta Cryst. B58, 38-51.

Vegas, A., Romero, A. \& Martínez-Ripoll, M. (1991). Acta Cryst. B47, $17-23$.

Vegas, A. \& Santamaría-Pérez, D. (2003). Z. Kristallogr. In the press. Walz, L., Heinau, M., Nick, B. \& Curda J. (1994). J. Alloys Comput. 216, 105-112.

Wardle, R. \& Brindley, G. W. (1972). Am. Mineral. 57, 732-750.

Wells, A. F. (1975). Structural Inorganic Chemistry. Oxford: Clarendon Press.

Westrik, R. \& McGillavry, C. H. (1954). Acta Cryst. 7, 764-767.

Winkler, H. G. F. (1974). Petrogenesis of Metamorphic Rocks. Berlin: Springer Verlag.

Worlton, T. G. \& Beyerlein, R. A. (1975). Phys. Rev. B, 12, 1899 1907.

Yamaguchi, G. \& Yanagida, H. (1959). Bull. Chem. Soc. Jpn, 32, 1264 1265.

Zak, Z. (1980). Z. Anorg. Allg. Chem. 460, 81-85.

Zintl, E. \& (1939). Angew. Chem. 52, 1-6. 